\title{
1,3-Dicarbonyl compounds in stereoselective domino and multicomponent reactions
}

\author{
Damien Bonne, Yoann Coquerel, Thierry Constantieux and Jean Rodriguez*
}

Aix-Marseille Université - Institut des Sciences Moléculaires de Marseille, iSm2 - UMR CNRS 6263

Faculté des Sciences et Techniques - Center St Jérôme - Case 531-13397 MARSEILLE Cedex 20-France

\begin{abstract}
Modern organic synthesis focuses on the discovery and the development of stereoselective multiple bond-forming transformations allowing the creation of several covalent bonds in a single operation. Hence, the number of steps required to obtain a target molecule is reduced, which nicely answers to the efficiency and economy criteria of "green chemistry". In this context, 1,3-dicarbonyl compounds are exceptional synthetic platforms due to the presence of four contiguous reaction sites. This functional group density allows cascades of elemental steps from simple substrates leading to the selective formation of elaborated molecular architectures. displaying a large functional diversity.
\end{abstract}

\section{General introduction}

Contemporaneous research in organic synthesis focuses on economy. Indeed, the efficiency of a synthetic sequence is more than ever corroborated with its conciseness and sustainability issues, as witnessed by the tremendous efforts currently directed at the development of multiple bond-forming ${ }^{1}$ and catalytic chemical processes. ${ }^{2}$ The efficiency of a chemical synthesis can be measured by parameters such as selectivity and overall yield, of course, but also by its raw material, time, human resources and energy requirements, as well as the toxicity and hazard of the chemicals and the protocols involved. It is thus now recognized that the step count is one of the most important criteria when evaluating the efficiency of a synthesis.

If ingeniosity at the strategy level can allow some shortening in a synthetic plan, we believe that the most important contributions to step-economical synthesis have resulted, and will do so in future, from advances in synthetic methodology. More specifically, domino ${ }^{3}$ and multicomponent ${ }^{4}$ reactions are now the corner stone to the economy in synthesis. Domino or/and multicomponent reactions have largely been used for the synthesis of large libraries of heterocyclic potentially bioactive molecules, ${ }^{5}$ and to a lesser extent, the total synthesis of complex molecules. ${ }^{6}$ Some families of densely functionalized small molecules are particularly suited for use in these reactions. In this context, 1,3-dicarbonyl compounds are exceptional synthetic platforms owing to the presence of four contiguous reaction sites with an alternative electrophilic and nucleophilic character, which can be modulated by the nature of the substituants.

In this review, on the basis of selected examples, we will highlight the recent developments of 1,3-dicarbonyl compounds in domino and multicomponent reactions ${ }^{7}$ leading to chiral products, with an emphasize placed on work published in the last five years. ${ }^{8}$

\section{Diasteroselective domino reactions}

\subsection{1,3-Dicarbonyl compounds as bis-nucleophiles}

Domino processes involving 1,3-dicarbonyl compounds as bis-nucleophiles for the creation of at least two $\mathrm{C}-\mathrm{C}$ bonds are often initiated by a conjugate addition. An early example involved the use of a $\beta$-ketoester in such a reaction for the preparation of compound $\mathbf{6}$ in a single operation from the simple substrates $\mathbf{1}$ and $\mathbf{2}$ in the presence of base (Scheme 1). ${ }^{9}$ In this example, the domino sequence of the elementary steps is initiated by the 1,6-conjugate addition of $\mathbf{1}$ to the bis-unsaturated ester $\mathbf{2}$ to generate the enolate $\mathbf{3}$, which after tautomerization provided the more stable enolate 4 , which in turn underwent an intramolecular 1,4 conjugated addition to give the bicyclic enolate $\mathbf{5}$. The latter underwent a final Dieckmann cyclization to finally provide the tricyclic product 6 in $41 \%$ yield from 1 .

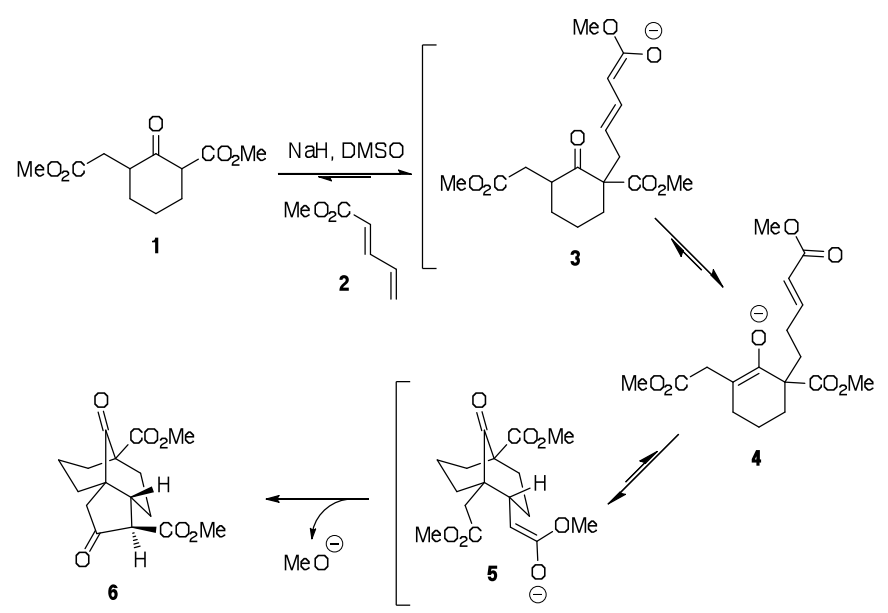

Scheme 1. Domino 1,6-addition-Michael-Dieckmann.

A related more recent example of such reactivity was reported by our group allowing a general access to 8-oxobicyclo[3.2.1] octanes from the $\beta$-ketoester 7 and unsaturated aldehydes $8{ }^{10}$ The domino sequence is initiated by a Michael addition, prolonged by an intramolecular aldolization to give the 8-oxo-bicyclo[3.2.1] octane 9 (Scheme 2). The diastereoselectivity of the reaction is highly dependent of the nature of the $\mathrm{R}^{1}-\mathrm{R}^{4}$ groups, and excellent transfer of chirality is observed starting form optically active cyclopentanones $7\left(\mathrm{R}^{2} \neq\right.$ $\mathrm{H})$. For example, the 8-oxo-bicyclo[3.2.1] octane (-)-9a is obtained in good yield from $(+)-7 \mathbf{a}\left(\mathrm{R}^{1}=\mathrm{O} t \mathrm{Bu}, \mathrm{R}^{2}=\mathrm{Me}\right)$. 


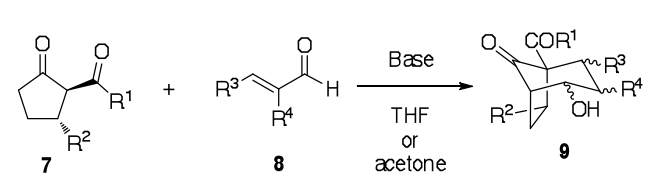

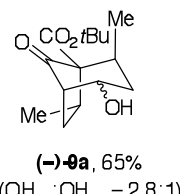

Scheme 2. Domino Michael-aldol carbocyclization.

A similar domino Michael-aldol strategy was developed for a total synthesis of the naturally occurring anti-Alzheimer product huperzine A. ${ }^{11}$ The tricyclic compound 11, synthetic precursor of huperzine $\mathrm{A}$, was prepared from the bicyclic $\beta$-ketoester $\mathbf{1 0}$ and metacrolein following a Michael-aldol sequence catalyzed by tetramethylguanidine (TMG, Scheme 3). In a second approach of the same natural product, the key intermediate $\mathbf{1 2}$ was obtained more efficiently by a palladium-catalyzed reaction with trimethylene methane from the same bicyclic $\beta$-ketoester $\mathbf{1 0}$.

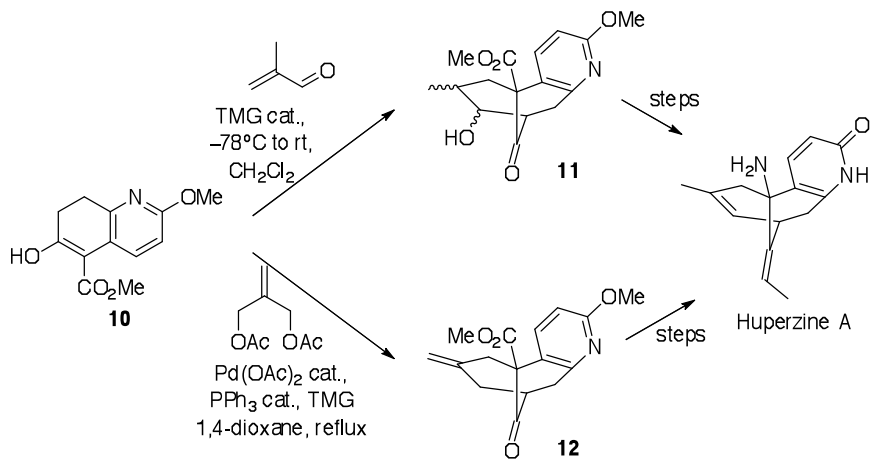

Scheme 3. Domino Michael-aldol toward huperzine A.

As illustrated above, the $C-C$ difunctionalization of 1,3dicarbonyl compounds involves the formation of enolates. In the following, the exploitation of the ambident character of enolates for $C-O$ difunctionalization will be presented.

We have proposed a short synthesis of the vinylidenetetrahydrofurans 15 via a $C-O$ alkylation sequence (Scheme 4). ${ }^{12}$ The cycloalkanone $\mathbf{1 3}$ reacted with 1,4dibromobut-2-yne in the presence of $\mathrm{K}_{2} \mathrm{CO}_{3}$ by initial $C$ alkylation to give the intermediate $\mathbf{1 4}$ which then underwent a $\mathrm{S}_{\mathrm{N}} 2$ ' $O$-cyclization according to the empirical rules established by Baldwin. ${ }^{13}$ The vinylidene compounds $\mathbf{1 5}$ can then be isomerized to the corresponding 1,3-dienes and used in subsequent Diels-Alder cycloadditions. ${ }^{14}$ This reactivity was explored with a variety of bis-electrophiles. With 1,3- and 1,4dihalides having $c i s$-like configurations, the $C$ - $C$ cycloalkylation products were obtained exclusively providing an access to bridged bicyclic compounds, while trans 1,4-dihalides (e.g. (E)1,4-dibromo-2-butene) gave only the $C$ - $O$ cycloalkylation products (Scheme 4). ${ }^{15}$
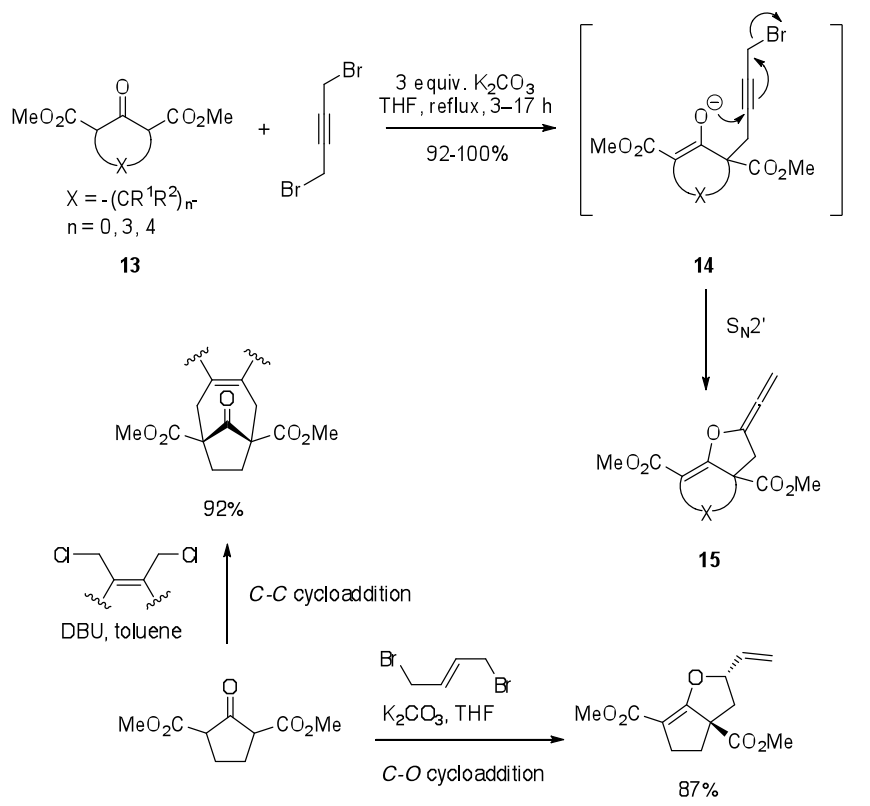

Scheme 4. Domino $C-O$ and $C-C$ cycloalkylation sequences.

Following these results, a related approach using 1,3dicarbonyl dianions was developped (Scheme 5). ${ }^{16}$ The treatment of $\beta$-ketoester 16 with at least two equivalents of strong base such as LDA generates the corresponding dilithio compound 17. For kinetic and thermodynamic reasons, this kind of dianion reacts with electrophiles preferentially at the $\gamma$ position. ${ }^{17}$ Thus, when dianion $\mathbf{1 7}$ is treated with a bis-electrophile such as $(E)$ 1,4-dibromo-2-butene, an initial intermolecular $\mathrm{S}_{\mathrm{N}} 2$ occurs to give the monoanion intermediate, which in turn undergoes a highly regio- intramolecular $\mathrm{S}_{\mathrm{N}} 2$ ' to give the vinyl-substituted tetrahydrofuran 18. Similarly to the above examples, this reaction is limited to the synthesis of five-membered ring due to favorable stereoelectronic factors. ${ }^{18}$

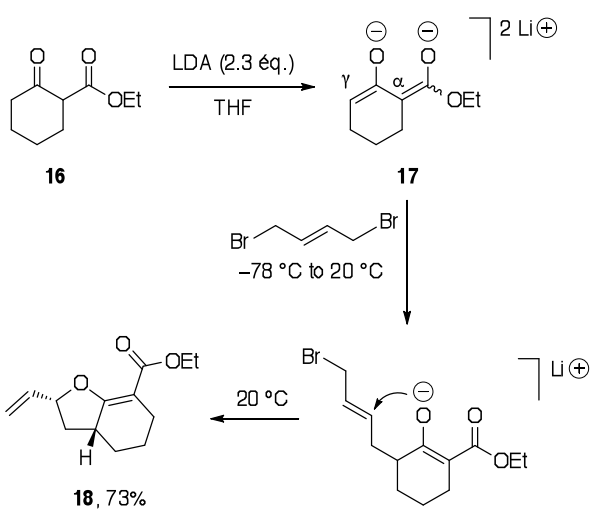

Scheme 5. Domino $C-O$ cycloalkylation sequence from 1,3-dicarbonyl dianion.

The use of the carbohydrate derivatives $\mathbf{2 0}$ as bis-electrophile in this domino reaction is interesting. Indeed, the regioselectivity of the $S_{N} 2 / S_{N} 2$ domino sequence with the dianion 19 can be controlled by the nature of the sulfonyl leaving-group. Thus the dianion 19 reacts with the tosyl derivative 20a by initial opening of the epoxide followed by the $O$-cyclization involving the substitution of the tosylate group to give 21a, whereas the triflate $20 \mathrm{~b}$ reacts first by substitution of the triflate, and then opening of the epoxide during the $O$-cyclization to give the regioisomeric product 21b (Scheme 6). ${ }^{19}$ 


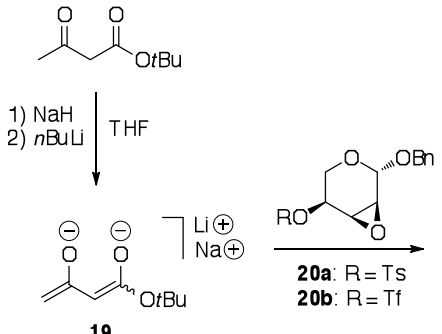

19

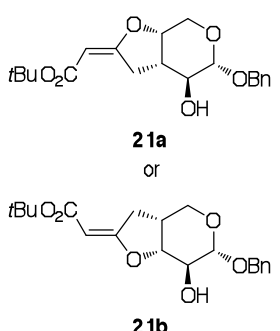

Scheme 6. Regioselective domino $C-O$ cycloalkylation sequence.

\subsection{Other reactivity of 1,3-Dicarbonyl compounds}

The use of 1,3-dicarbonyls as bis-electrophiles in domino processes for the preparation of chiral compounds is very limited. We can highlight here the recent utilization of malonyl dichloride in the key step of a synthetic approach to the polyprenylated phloroglucinol natural product clusianone (24, Scheme 7). Thus, the highly functionalized bicyclo[3.3.1]nonane framework of the natural product can be obtained in a single synthetic operation from the reaction of the silyl enol ether $\mathbf{2 2}$ with malonyl dichloride, a precursor of chloroacylketene, to give $\mathbf{2 3}$, which was then converted to clusianone (24) in few steps. ${ }^{20}$
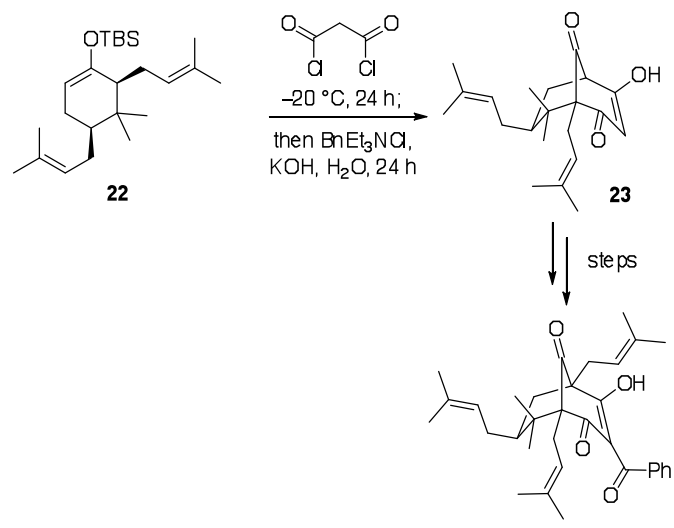

dusianone (24)

Scheme 7. Highlight of the total synthesis of clusianone (24).

In a few cases, 1,3-dicarbonyls have been used as both electrophilic and nucleophilic reaction partners to prepare chiral molecules. As mentioned above, dianions of type 25 react with electrophiles preferentially at the $\gamma$ position. If an aldehyde is used as electrophile, an aldolization at the $\gamma$ position occurs to give the intermediate alcoolate $\mathbf{2 6}$, which can then undergo an intramolecular lactonization to give the $\beta$-oxo- $\delta$-lactone 27 (Scheme 8). ${ }^{21}$

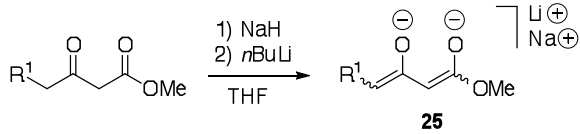

$$
\begin{aligned}
& \downarrow \mathrm{R}^{2} \mathrm{CHO}
\end{aligned}
$$

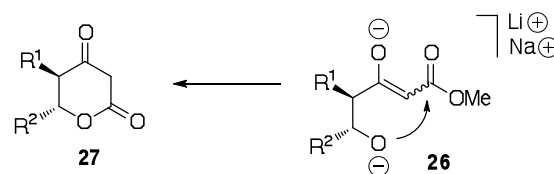

Scheme 8. Synthesis of $\beta$-oxo- $\delta$-lactone from 1,3-dicarbonyl compounds.

Another example of related reactivity involves the unsaturated ketoester 28. In this case, the electrophilic $\beta$ position is homologated to the $\delta$ position via the incorporation of a conjugated double bond. This approach was largely developed for the synthesis of steroids, and was recently applied to the total synthesis of the naturally occurring glycosilated steroid ouabaine $\left(32\right.$, Scheme 9). ${ }^{22}$ In the presence of base, the $\beta$-ketoester 28 first reacts by a diastereoselective Michael addition to the unsaturated $\beta$-ketoaldehyde $\mathbf{2 9}$ to give the intermediate stabilized enolate $\mathbf{3 0}$, which in turn undergo cyclization following an intramolecular Michael addition to give compound 31, a synthetic precursor of ouabaine (32). Enantioselective organocatalytic versions of related domino Michael-Michael reaction have been developed recently (see section 4.1).
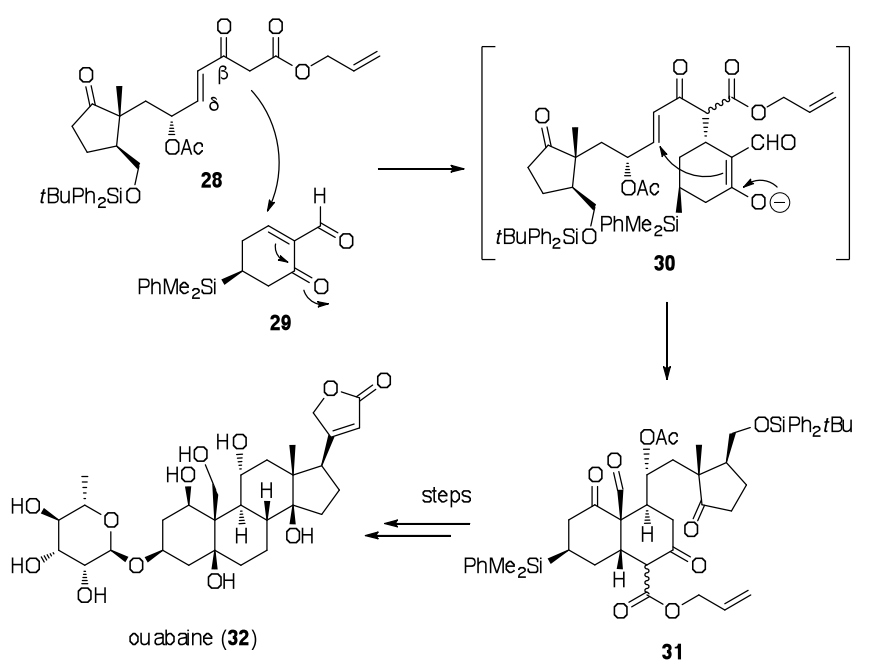

Scheme 9. Highlight of the total synthesis of ouabaine (32).

2-Diazo-1,3-dicarbonyl compounds are know to undergo thermal or photochemical Wolff rearrangement to give the corresponding reactive acylketenes. ${ }^{23}$ Recently, it was demonstrated that such a rearrangement could occur under dielectric heating (microwave irradiation), and that the transient acylketene can be trapped in a domino process with a variety of nucleophiles including alcohols, amines or thiols in nearly quantitative yields to provide a general access to $\alpha$-carbonylated cycloalkanones (Scheme 10). ${ }^{24}$ This approach allowed the easy introduction of chiral auxiliaries ( $\mathbf{3 5}$ and $\mathbf{3 7}$ for example), the preparation of otherwise difficultly available compounds (33, 35 and 36 for example), and overall, proved superior to existing approaches in scope and eco-compatibility. 

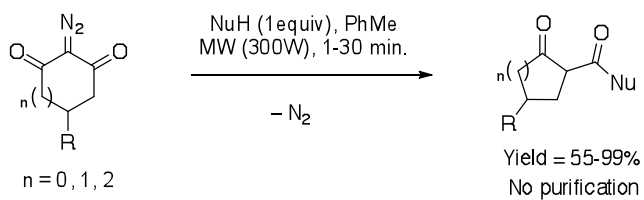

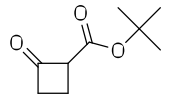

$33,84 \%$
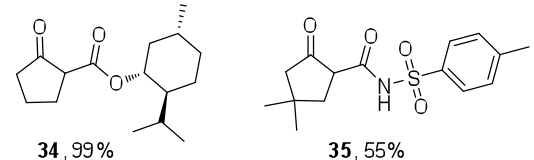

$35,55 \%$

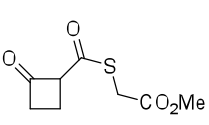

$36,95 \%$

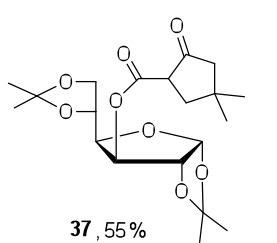

$38,99 \%$
Scheme 10. Domino Wolff rearrangement-nucleophilic addition.

\section{Diasteroselective multicomponent reactions}

In this section, examples are organized with respect to the proposed nature of the first reaction of the sequence.

\subsection{MCRs based on the Hantzsch reaction}

1,4-dihydropyridines (1,4-DHPs) are an important classe of bioactive molecules and are also interesting biomimetic reducing agents. The synthesis of 1,4-DHPs is generally achieved using the four-component Hantzsch reaction, first reported in $1882,{ }^{25}$ which involves the one-pot condensation of an aldehyde, two equivalents of a $\beta$-ketoester and ammonia or a synthetic equivalent (Scheme 11). The reaction proceeds through the condensation of in situ formed alkylidene malonate 39 and enaminoester derivative $\mathbf{4 0}$, followed by a cyclodehydration affording the symmetric heterocycle 41. Cyclic 1,3-diketones can also participate in this multicomponent sequence, leading to hydrogenated acridine derivatives. ${ }^{26}$

$$
{ }_{40}
$$

Scheme 11. General scheme of the Hantzsch's 1,4-DHPs synthesis.

Alternatively, when only one equivalent of 1,3-dicarbonyl is used in combination with one equivalent of $\beta$-ketoester, chiral 1,4-DHPs may be obtained. Several diastereoselective approaches have been studied for the preparation of optically active 1,4-DHPs. For example, the use of one of the partners under enantiomerically pure form may be a solution. Thus, Rose and Draeger described in 1992 a four-component condensation between 1,3-cyclohexanedione,

$3,4-$ (methylenedioxy)benzaldehyde, ammonia and a mandelic ketoester derivative $\mathbf{4 2}$, leading to the expected dihydropyridine 43 in up to $98 \%$ diastereomeric excess (Scheme 12). ${ }^{27}$

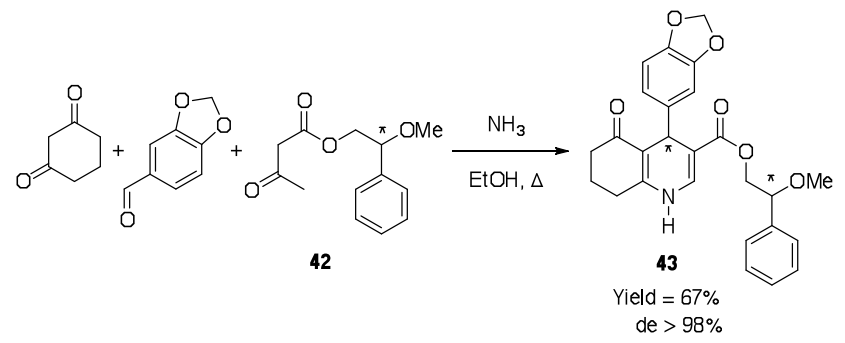

Scheme 12. Diastereoselective synthesis of chiral 1,4-DHPs.

Optically pure 1,4-DHPs may also be accessed through chemical resolution, as illustrated by the synthesis of the potassium channel opener ZD0947 (Scheme 13). ${ }^{28}$ An unsymmetrical Hantzsch reaction afforded an unusually stable tetrahydropyridine 44, which led to the desired bioactive product after dehydration, cleavage of the ester, and resolution of the corresponding acid with $(S)-(\alpha)$-methylbenzylamine. An organocatalytic enantioselective version of this four-component synthesis of bicyclo-1,4-DHPs was recently reported in the literature (see section 4.2).

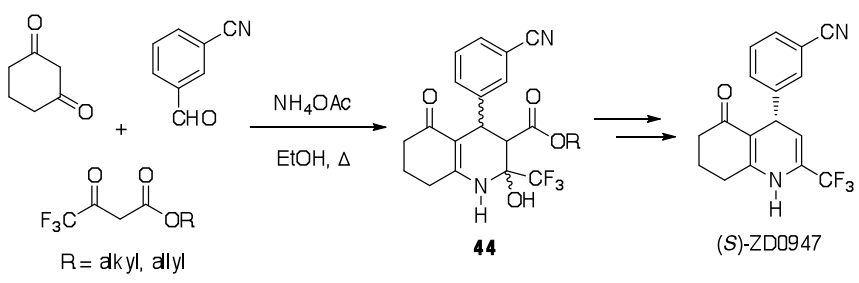

Scheme 13. Synthesis of $(S)$-ZD0947, a potassium channel opener.

Another possibility for the efficient synthesis of unsymmetrical DHPs relies on the condensation between aldehydes and 1,3-dicarbonyls in the presence of a preformed enamino ester intermediate. Thus, starting from an aldehyde and a enaminoester, the asymmetric synthesis of 1,4-DHP $C$ glycoconjugate was achieved. ${ }^{29}$ Recently, the same group developed the first organocatalyzed C-glycosyl aldehyde $45 / \beta$ ketoester/enamine 46 three-component variant of the Hantzsch reaction, leading to the formation of symmetrically and unsymmetrically substituted DHP C-glycoconjugates 47 of biological relevance, with diastereomeric excesses up to $95 \%$ (Scheme 14). ${ }^{30}$
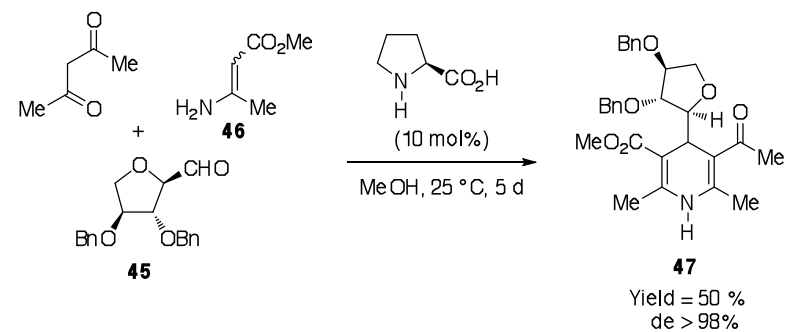

Scheme 14. Organocatalytic diastereoselective synthesis of DHP $C$ glucoconjugates.

This modified Hantzsch approach has recently been exploited for the stereoselective synthesis of pyrazolo[4,3-c] quinolizin-9ones 48 (Scheme 15). ${ }^{31}$ Microwave irradiation of a mixture of dimedone, aminopyrazole and aromatic aldehyde in the presence of $t \mathrm{BuOK}$ led to these heterocyclic compounds in moderate to good yields. The intermediate unsymmetric Hantzsch product 49 undergoes a ring opening step followed by an intramolecular transamidation to give finally $\mathbf{4 8}$. 


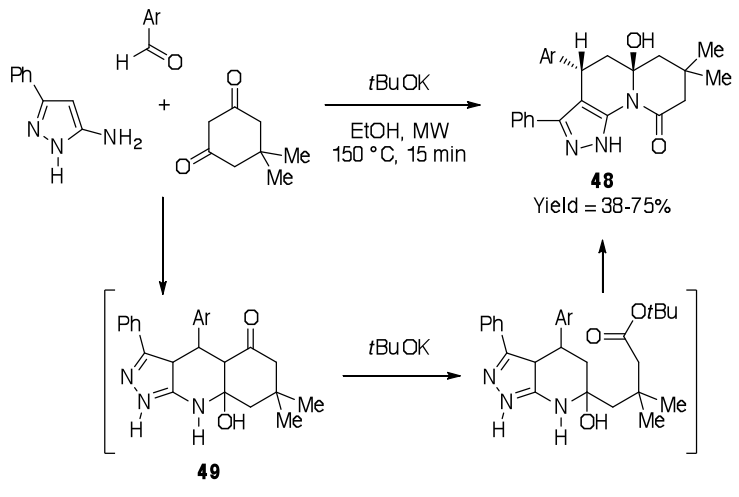

Scheme 15. Microwave-assisted synthesis of pyrazolo[4,3-c]quinolizin-9ones.

Finally, when the enamine partner is replaced by a guanidine system, the modified MCR evolves through a Knoevenagel-azaMichael sequence, leading to polyheterocycles 50 of biological interest (Scheme 16). ${ }^{32}$ Thus, the condensation of 2-amino-1,3,4triazole, an aldehyde and a 1,3-dicarbonyl substrate in water at room temperature afforded the corresponding bicyclic hemiaminals $\mathbf{5 0}$ in moderate to good yields. It is noteworthy that in most of the cases, only one of the four possible diastereomers is formed in this environmentally benign catalyst-free sequence.

$$
\text { }
$$

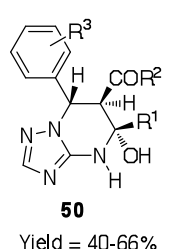

Scheme 16. Multicomponent $[1,2,4]$ triazolo[2,1-b]quinazolinones.

synthesis

of $\quad 5,6,7,8$-tetrahydro

\subsection{MCRs based on the Biginelli reaction}

The Biginelli reaction, discovered by Pietro Biginelli in $1893,{ }^{33}$ is a multicomponent reaction allowing the synthesis of 3,4-dihydropyrimidin-2-(1H)-ones or -thiones (DHPMs) 51 by reacting an urea or thiourea, a 1,3-dicarbonyl derivative and an aldehyde (Scheme 17). The increasing interest in DHPMs is mainly due to their therapeutic and pharmacological properties. ${ }^{34}$

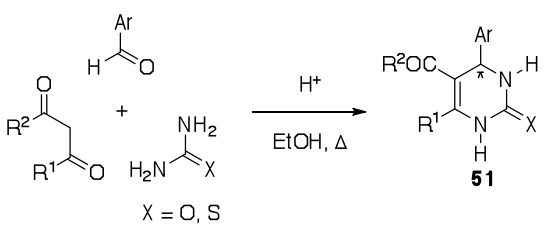

Scheme 17. General scheme of the Biginelli reaction.

Biginelli products contain a stereogenic center, and the influence of the absolute configuration on the biological activity has been investigated. Indeed, as two enantiomers may perform different or even opposite activities, ${ }^{35}$ the development of representative methods to approach enantioenriched DHPMs is a task of primary importance. ${ }^{36}$ Initially, chemical resolution by conversion of racemic compounds into diasteromers was the method of choice, affording for example optically pure bioactive DHPMs such as SQ-32926 ${ }^{37}$ and the two enantiomers of monastrol $^{38}$ (Figure 1). Alternatively, resolution of racemic DHPMs was also attempted via enzymatic hydrolysis of ester moieties, ${ }^{39}$ as illustrated by the preparation of a precursor of $(S)$ L-771688. ${ }^{40}$<smiles>N#CC1C(=O)NC(=O)N(C(=O)Nc2cccc([N+](=O)[O-])c2)C1C(N)=O</smiles>

(R)-SQ-32926<smiles>CC(=O)OC(=O)C1=C(C)NC(=S)N[C@H]1c1cccc(O)c1</smiles>

(S)-Monastol<smiles>COCC1=C(C(C)=O)NC(=O)NC1c1ccc(F)c(F)c1</smiles>

precursor of precursor of
$(S)-$ - -771688
Figure 1. Optically pure DHPMs obtained via chemical or enzymatic kinetic resolution.

Optically active DHPMs were also prepared through auxiliary-assisted asymmetric Biginelli synthesis, using chiral starting materials such as $C$-glycosyl substrates. ${ }^{29 a}$ As an illustration, the synthesis of two diastereoisomers of monastrol analogues $\mathbf{5 2}$ bearing the ribofuranosyl moiety has been successfully achieved (Scheme 18). ${ }^{41}$ On the contrary, all efforts for the synthesis of optically active related DHPMs through Biginelli reaction involving (-)-menthol-derived acetoacetate, were unproductive since a 1:1 mixture of unseparable diastereomers were obtained. ${ }^{42}$

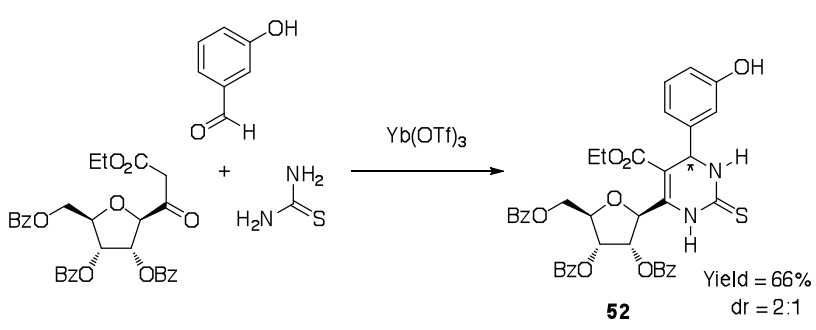

Scheme 18. Synthesis of glycosyl analogues of monastrol.

\subsection{MCRs based on the Mannich reaction}

The Mannich reaction consists on the condensation of a C-Hactivated compound with a primary or a secondary amine and a non-enolizable aldehyde or ketone to afford $\beta$-aminocarbonyl derivatives known as Mannich bases. This sequence is of great use for the construction of cyclic and acyclic nitrogen-containing molecules, and numerous variants have been published. Among them, the $\mathrm{CoCl}_{2}$-catalyzed coupling between a 1,3-dicarbonyl compound 53, an aromatic aldehyde 54, and acetonitrile in the presence of acetyl chloride, ${ }^{43}$ provides a general access to $\beta$ acetamido carbonyl compounds 55 (Scheme 19). These products are the building blocks of numerous pharmaceutical and biological compounds, and they can be used as precursors of 1,3amino alcohols, $\beta$-amino acids ${ }^{43}$ and $\gamma$-lactams. ${ }^{44}$

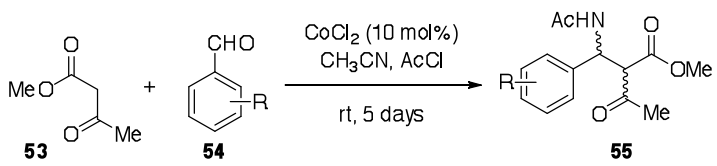

Scheme 19. Multicomponent synthesis of $\beta$-acetamido carbonyl derivatives.

A large number of catalysts have been reported for this reaction, with diastereomeric ratio ranging from $50 / 50$ to $98 / 2{ }^{46}$ Recently, selectfluor has been described as an efficient green catalyst for this transformation, offering advantages such as shorter reaction times and high anti-selectivity, especially from $\alpha$-substituted ketones. ${ }^{47}$ Finally, a variant was reported recently 
involving acetamide in the presence of trimethylchlorosilane. ${ }^{48}$ The latter compound acts as a Lewis acid for activation of the aldehyde partner.

The Mannich reaction is also of great use for the construction of heterocyclic targets, as illustrated by the recent reports on the synthesis of 1,4-diazepane derivatives 59 (Scheme 20). Kita's group $^{49}$ and our group $^{50,51}$ reported independently a cyclodehydrative three component synthesis of these heterocyclic seven-membered rings of biological interest from 1,3-dicarbonyl compounds 56, aromatic aldehydes and 1,2-diamines 57. The reaction involves the formation of an intermediate $\mathbf{5 8}$ bearing imine and enamino ester functionalities, which then evolves to the final product via an intramolecular Mannich-type condensation. The latter step of the sequence corresponds to a $\gamma$ functionalization of the starting 1,3-dicarbonyl. The reaction may be conducted either in refluxing 1,2-dichlorethane in the presence of para-toluene sulfonic acid (method A) or $4 \AA$ molecular sieves (method B) as catalyst, or under solvent- and catalyst-free conditions (method $\mathrm{C}$ ). The latter conditions were particularly efficient when $\beta$-ketoamides were used as substrates. It is noteworthy that 1,2-phenylenediamine was not effective in this multicomponent reaction, but the access to the corresponding 1,5-benzodiazepine derivatives were made possible by the development of a sequential one-pot protocol involving the preliminary acid-catalyzed formation of an enamino ester from the 1,2-diamine and a 1,3-dicarbonyl. ${ }^{52}$

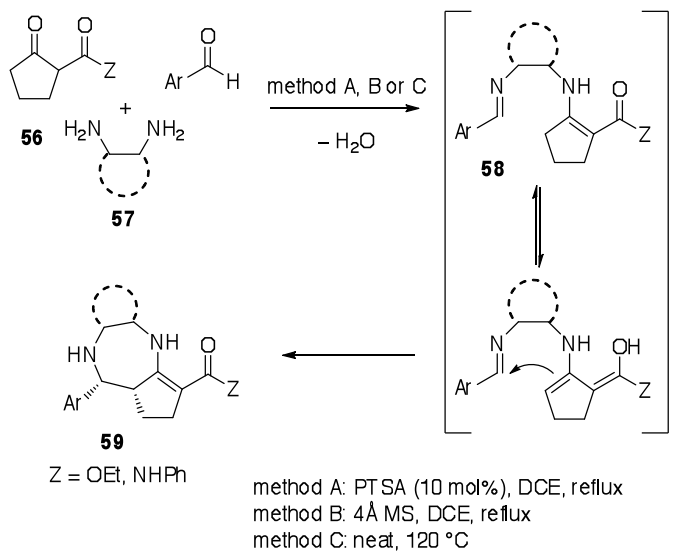

Scheme 20. Three-component synthesis of 1,4-diazepane derivatives.

\subsection{MCRs based on the Knoevenagel reaction}

The Knoevenagel reaction is the condensation of aldehydes or ketones with active methylene compounds, usually in the presence of a weakly basic amine. ${ }^{53}$ The resulting highly reactive product 60 can undergo inverse demand hetero-Diels-Alder reaction with a dienophile $\mathbf{6 1}$ to afford functionalized dihydropyrans 62 (Scheme 21). The reaction can be performed as a "two-component reaction", by putting a 1,3-dicarbonyl derivative and an aldehyde containing a dienophile moiety together, or as a "three-component reaction", through the use of a mixture of a 1,3-dicarbonyl, an aldehyde and a dienophile. This multicomponent sequence, known as the "Domino-Knoevenagel Hetero-Diels-Alder reaction", was discovered and intensively studied by the group of Tietze. ${ }^{54}$ As an illustration of its potentialities, this domino sequence was reported as a successful key step in the first enantioselective syntheses of Ipecacuanha alkaloid emetine and Alagium alkaloid tubolisine. ${ }^{55}$

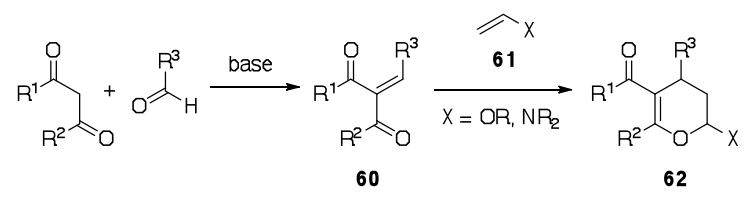

Scheme 21. The « Domino-Knoevenagel-Hetero-Diels-Alder» sequence.

In this context, some recent examples concern the reactivity of 1,4-benzoquinones and pyrazolones as 1,3-dicarbonyl equivalents under microwave irradiation. Thus, the sequence has been successfully extended to the regioselective multicomponent construction of bis-pyrano-1,4-benzoquinone derivatives $\mathbf{6 5} \mathbf{a}$ and 65b from 2,5-dihydroxy-1,4-benzoquinone (63), paraformaldehyde and an alkene (Scheme 22). ${ }^{56}$ Depending on the alkene moiety, the reaction yielded only the linear tri-, pentaor heptacyclic product in a 1:1 diastereomeric ratio, as illustrated with indene (64).

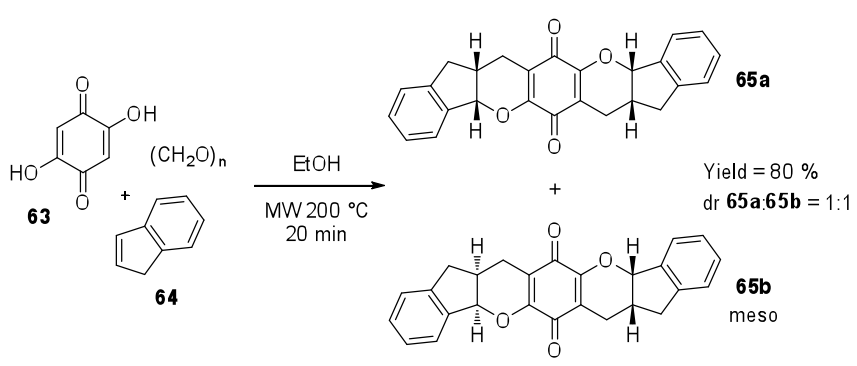

Scheme 22. Example of heptacyclic bis-pyrano-1,4-benzoquinone derivatives.

An organocatalyzed microwave-assisted KnoevenagelHetero-Diels-Alder reaction was reported for the synthesis of 2,3-dihydropyran[2,3-c]pyrazoles 67 from pyrazol-2-one 66 as masked synthetic equivalent of 1,3-dicarbonyl (Scheme 23). ${ }^{57}$ Using proline derivatives as catalyst in $t \mathrm{BuOH}$, the two diastereomers of the desired product were isolated in good yields with a 4:1 diastereomeric ratio.

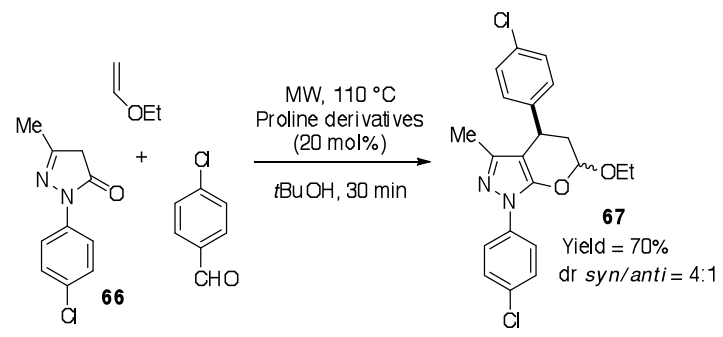

Scheme 23. Asymmetric synthesis of 2,3-dihydropyran[2,3-c]pyrazoles from pyrazol-2-one.

The Knoevenagel reaction may also be combined with a Michael addition in multicomponent sequences. During a study on the synthesis of non-natural trytophan and tryptamine derivatives, the condensation of indole with Meldrum's acid and aldehyde $\mathbf{6 8}$ in acetonitrile, in the presence of a catalytic amount of D,L-proline, afforded the corresponding adduct 69 in good yield as only one diastereomer (Scheme 24). ${ }^{58}$ This variant of the Yonemitsu reaction was successfully applied to the asymmetric synthesis of tryptamine $e^{59}$ and tetrahydro- $\beta$-carboline ${ }^{60}$ derivatives. 


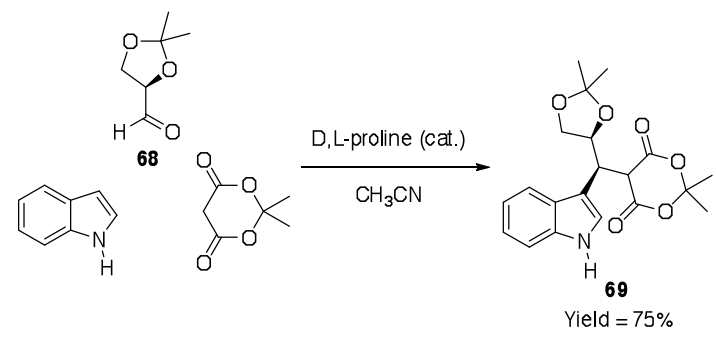

Scheme 24. Domino Knoevenagel-Michael reaction.

A Knoevenagel-based reaction was recently reported for the construction of bis-heterocycle (Scheme 25). ${ }^{61}$ The reaction is a four-component Knoevenagel-Michael-oxa-cyclisation involving malonitrile, an aldehyde or a ketone, a $\beta$-ketoester and hydrazine. This methodology was intensively developed with a wide range substrates to form a series of these fused heterocyclic skeletons, and interestingly enough, when a bulky aromatic aldehyde (e.g $\mathrm{R}^{2}=2$-methoxynaphtyl $; \mathrm{R}^{3}=\mathrm{H}$ ) was used two atropoisomers were isolated in a 2:1 ratio.

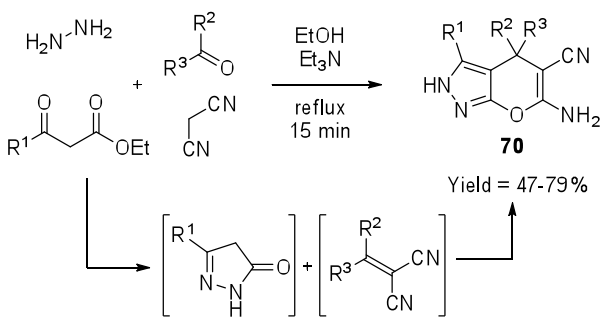

Scheme 25. Four-component synthesis of highly substituted dihydropyranopyrazole derivatives.

Knoevenagel reaction has also been combined with 1,3dipolar cycloaddition to allow the formation of challenging bispiropyrrolidine derivatives 72 (Scheme 26). ${ }^{62}$ A mixture of 1,3-indanedione, an aldehyde, sarcosine and a cyclic 1,2-dione in refluxing ethanol without any catalyst gave bispiropyrrolidine derivatives $\mathbf{7 2}$ as a single diastereomer. This highly regio- and stereoselective four-component Knoevenagel-Huisgen cycloaddition sequence is of great interest for the synthesis of such spiropyrrolidines which are potential antileukemic and anticonvulsant agents also exhibiting antiviral properties. A reasonable mechanism involves a twofold role of sarcosine, which actes both as catalyst for the Knoevenagel condensation and as key reaction partner for in situ formation of the dipolarophile $\mathbf{7 3}$.

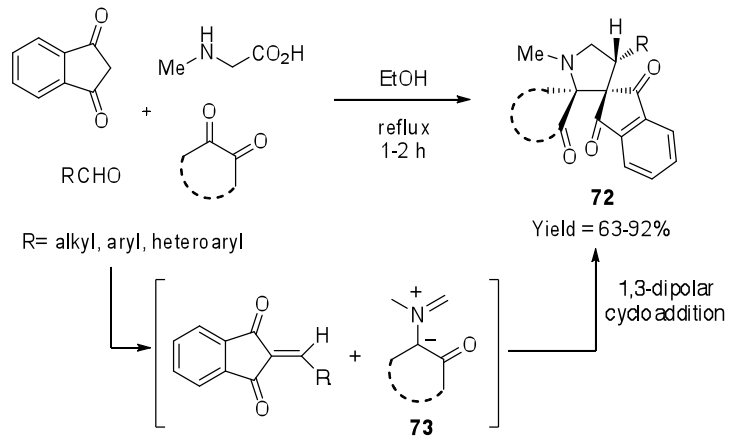

Scheme 26. Four-component synthesis of functionalized bispiropyrrolidines.
Finally, a domino multicomponent reaction combining a Lewis acid catalyzed Knoevenagel condensation, a Nazarov cyclisation and an electrophilic fluorination was recently reported for the highly diastereoselective synthesis of fluorinated 1indanone derivatives 74 (Scheme 27). ${ }^{63}$ Thus, condensation of an aromatic $\beta$-ketoester $\mathbf{7 5}$ with an aldehyde in the presence of $N$ fluorobenzenesulfonimide (NFSI) and $\mathrm{AlCl}_{3}$ in nitroethane at room temperature, afforded the desired heterocycles with high trans stereoselectivity.

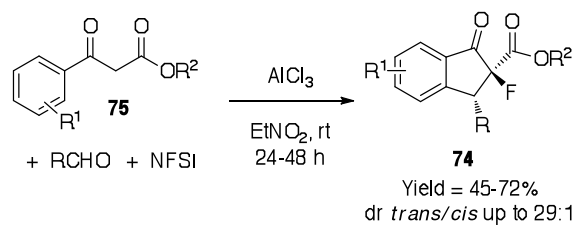

Scheme 27. Three-component synthesis of fluorinated trans-1-indanones

\subsection{MCRs based on the Michael addition}

In its original form, the Michael addition consisted on the addition of diethyl malonate across the double bond of ethyl cinnamate in the presence of sodium ethoxide, to afford a substituted pentanedioic acid ester. ${ }^{64}$ Currently, all reactions that involve a 1,4-addition of stabilized carbon nucleophiles to activated $\pi$-systems are known as Michael additions. Among the various reactants, enolates derived from $\beta$-dicarbonyl compounds are substrates of choice due to their easy deprotonation under mild conditions. Although this addition with such substrates is an old, but still very powerfull and simple reaction, it came to be of interest for MCRs only recently, and has emerged as promising approach with a wide synthetic potential in heterocyclic synthesis. In this context, we will focus in this paragraph on recent selected examples of the application of Michael additionbased $\mathrm{MCRs}^{65}$ to the synthesis of chiral polysubstituted heterocycles ${ }^{66}$ in the five- to seven-membered series.

The first Michael addition-based MCR with 1,3-dicarbonyls was reported by Eschenmoser and co-workers in $1979 .{ }^{67}$ They described a fragmentational approach to macrolides, starting from substrates which are accessible through a three-component condensation of acrolein, 2-methyl-1,3-cyclohexanedione and dimethylmalonate. However, since the publication of these preliminary results, such MCRs remained unexplored for over 20 years. In 2001, we developed the first multicomponent domino reaction between 1,3-dicarbonyls, $\alpha, \beta$-unsaturated aldehydes or ketones and $\omega$-nucleophilic functionalized primary amines $\mathbf{7 6}$ in the presence of molecular sieves, providing a route to polyheterocyclic compounds of synthetic, biological and pharmaceutical interests (Scheme 28). ${ }^{68}$ From a mechanistic point of view, the key step of this sequence is the formation of an iminium intermediate $\mathbf{7 7}$ or $\mathbf{7 8}$, which is trapped in situ by the nucleophilic function of the amine partner. The structure of the corresponding products is highly dependent of the nature of the amine. Indeed, diamines, aminoalcohols and aminothiols led selectively to the formation of fused polyheterocyclic $N / N-, N / O$ and $N / S$-aminals with partial to total anti selectivity, while $o$ hydroxyaniline afforded a spiro-type tetracyclic compound 79 as a single diastereomer (Figure 2). 


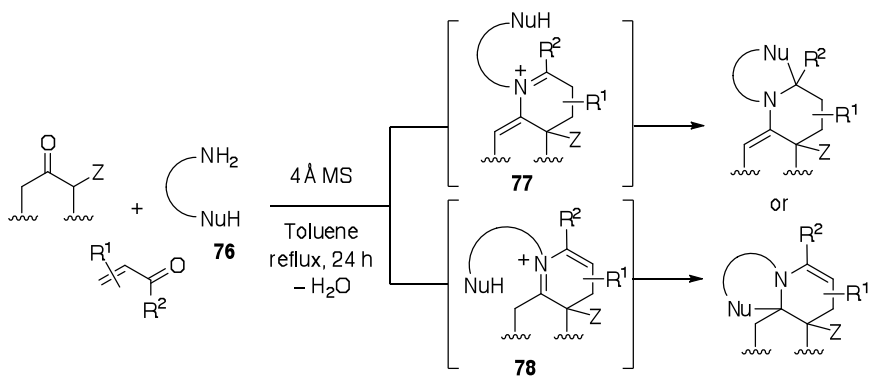

Scheme 28. General scheme for the multicomponent synthesis of fused- or spiro-type polyheterocycles.

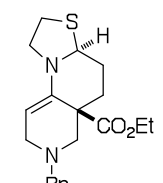

$\mathrm{Bn}$ $66 \%$
dr anti/syn $=70: 30$<smiles>CCOC12CCC3OCc4ccccc4N3C3=CCN(Br)CC1(CC)C3O2</smiles>

$\mathrm{dr}$ anti/syn $=60: 40 \quad \mathrm{dr}$ anti/syn $=100: 0$

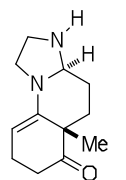

$52 \%$

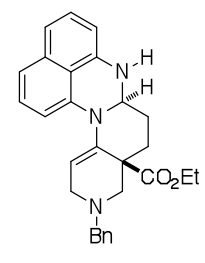

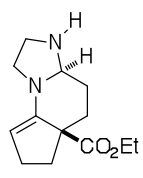

$36 \%$ anti/sy $n=100: 0$

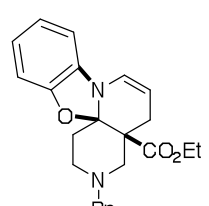

$79,67 \%$
Figure 2. Polycyclic $N / N-, N / O$ - and $N / S$-aminal synthesis via Michaelinitiated MCRs.

More recently, an extrapolation of this work was proposed for the three-component condensation of acrolein, (S)-2phenylglycinol and various acyclic 1,3-dicarbonyls in toluene in the presence of $4 \AA$ molecular sieves for the preparation of bicyclic functionalized tetrahydropyridines 80 (Scheme 29). ${ }^{69}$ These heterocycles may be used as chiral building blocks for the synthesis of alkaloids, as illustrated by the total synthesis of (-)lupinine in five steps and $29 \%$ overall yield.

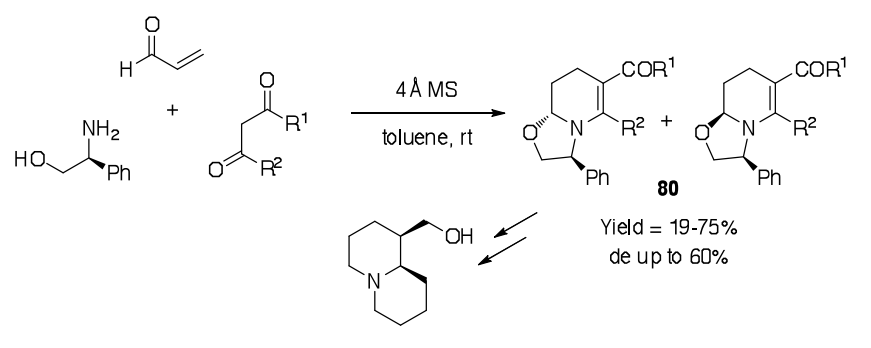

(-)-Lupinine

Scheme 29. Three-component synthesis of bicyclic tetrahydropyridines.

The introduction of a functionalized pyrrole $\mathbf{8 1}$ as the amine partner in this sequence allowed us to propose a highly efficient access to original pyrrolopiperazine and azasteroid-like scaffolds. The key-step consists on the formation of an ene-iminium intermediate 82, in situ trapped through a Pictet-Spengler-type cyclization. As an illustration of the stereoselective potential of this transformation, we were able to prepare a tetracyclic compound $\mathbf{8 3}$ with an azasteroid skeleton, in high yield and as a single 1,4-trans diastereomer (Scheme 30). ${ }^{70}$

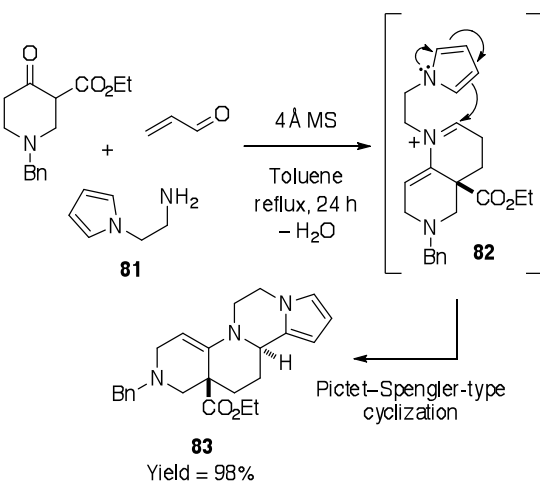

Scheme 30. Totally diastereoselective three-component synthesis of original pyrrolopiperazine scaffolds.

Alternatively, the introduction of various unfunctionalized primary amines into this three-component domino reaction resulted in the formation of other families of polyheterocycles. Thus, the reaction between an ethoxycarbonyl piperidone 84, acrolein and a primary amine in refluxing toluene in the presence of molecular sieves gave either 1,6-hydronaphthyridines $\mathbf{8 5}$ or amino azabicyclo[3.3.1]nonanones 86, depending on the substitution of the amines (Scheme 31). ${ }^{71}$

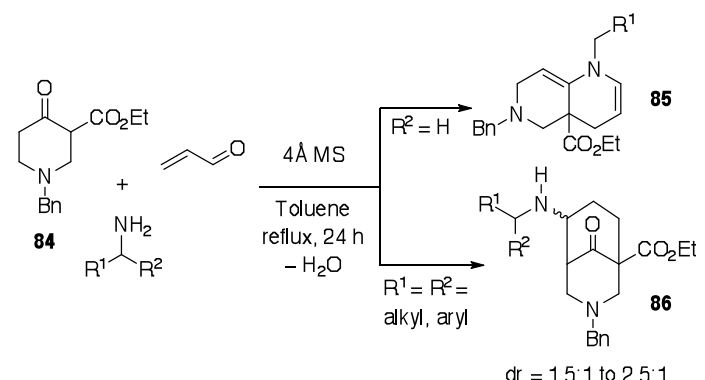

Scheme 31. Selective formation of 1,6-naphthyridines vs azabicyclo[3.3.1]nonanones

Starting from quite similar reagents, i.e. alkylamines, $\beta$ ketoesters and chalcones, but replacing molecular sieves by CAN as catalyst in ethanol, a totally diastereoselective synthesis of cis4,6-disubstituted 2-alkylaminocyclohexene-1-carboxylic esters 87, precursors of densely functionalized $\beta$-aminoesters containing four stereocenters, was reported (Scheme 32). ${ }^{72}$

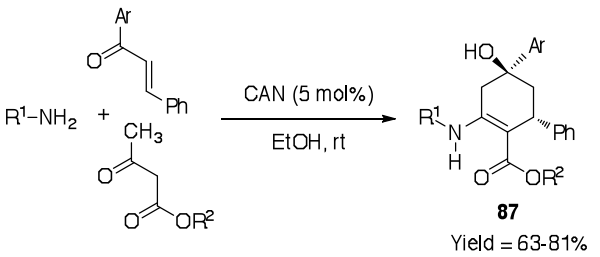

Scheme 32. CAN-catalyzed preparation of 2-alkylamino-1-cyclohexene-1carboxylic esters.

Finally, the highest level of complexity for this threecomponent reaction was reached when $\beta$-ketoamides $\mathbf{8 8}$ were used as substrates. We demonstrated that these particular 1,3dicarbonyls could be involved not only as substrates but also as nucleophilic partners through the highly diastereoselective synthesis of scaffolds $\mathbf{8 9}$ containing an original 2,6diazabicyclo[2.2.2] octane skeleton $(2,6-\mathrm{DABCO}) .{ }^{73}$ In this transformation, two different iminium intermediates 90 and 91 were successively generated and trapped by two different nucleophiles, one being the substrate itself and the other one resulting from the heterofunctionalization of the amine partner (Scheme 33). 


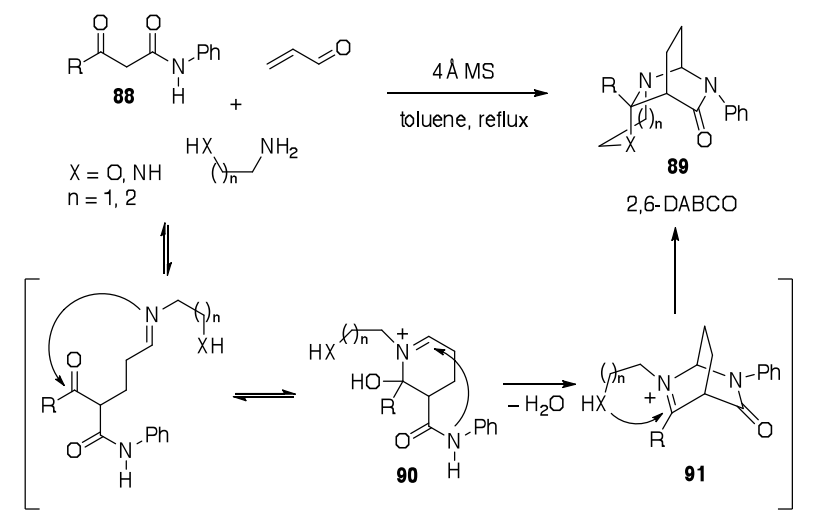

Scheme 33. Three-component synthesis of 2,6-DABCO scaffolds.

The Michael-aldol domino sequence between $\beta$-ketoesters of type 92 and $\alpha, \beta$-unsaturated aldehydes leading to 8-oxobicyclo[3.2.1] octanes of type $\mathbf{9 3}$ was presented above (see Scheme 2). When the same reaction is conducted in methanol, the latter can react as a nucleophile with the 8-oxobicyclo[3.2.1] octane 93, and promotes the retro-Dieckamnn type fragmentation of the bicyclic compound into the sevenmembered rings 94 or 95 (Scheme 34 ). ${ }^{74}$ This fragmentation is favored by the relaxation of the ring tension of the 8-oxobicyclo[3.2.1] octane intermediate, while the analogous less strained bicyclo[3.3.1]nonane do not undergo the fragmentation under these conditions. The reversible character of the two first elemental steps of this domino reaction (Michael addition and aldolization) combined with a highly selective retro-Dieckmann fragmentation allow a highly diastereoselective access to a variety of polysubstituted and functionalized seven-membered rings starting from simple and cheap substrates under user and environmentally friendly conditions. This reaction, which was denominated MARDi cascade following the acronym of the domino sequence Michael/ㅌldol/Retro-Dieckmann, is a multicomponent reaction and the final product is the condensation product of the $\beta$-ketoester 92, the $\alpha, \beta$-unsaturated aldehyde and methanol. In the case of metacrylic aldehydes $\left(\mathrm{R}^{1}=\right.$ $\mathrm{H}, \quad \mathrm{R}^{2} \neq \mathrm{H}$ ), the MARDi cascade is prolonged by an intramolecular lactonization and an elimination to give the cycloheptene carboxylic acid $\mathbf{9 5}$. The MARDi cascade is very general and can also be realized starting from $\beta$-ketosulfones with complementary diastereoselectivity and reactivity ${ }^{75}$ or in the heterocyclic series (Figure 3 ). ${ }^{76}$ The reaction allows the control of up to five newly created stereocenters, and a complete chiral induction in the case an optically active $\beta$-ketoester precursor. An application of the MARDi cascade to the synthesis of the tricyclic ring system of guaianolide natural products was reported recently. ${ }^{77}$

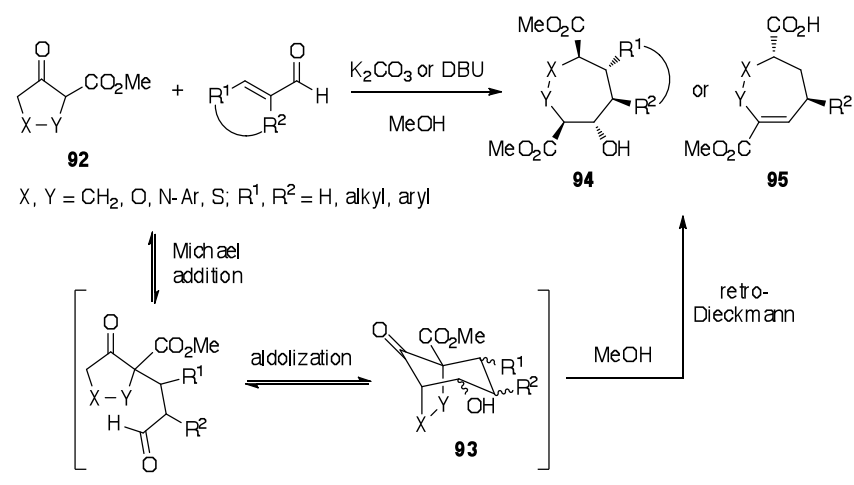

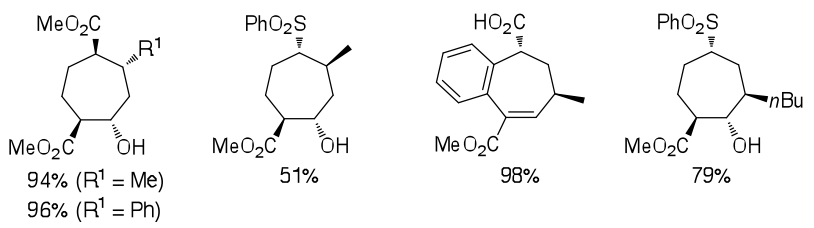

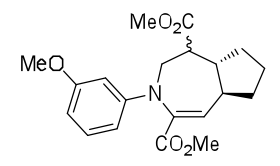

$32 \%(\mathrm{dr}=1.6: 1)$

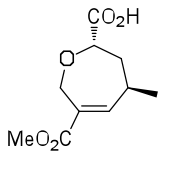

$42 \%$

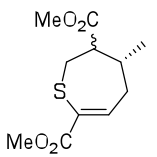

$58 \%(d r=5: 1)$

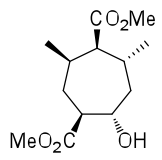

$43 \%$ (ee $>99 \%$ )
Figure 3. Selected examples of products obtained by the MARDi cascade.

\subsection{MCRs based on other reaction}

As mentioned above, 2-diazo-1,3-dicarbonyl compounds can undergo an efficient Wolff rearrangement under microwave irradiation to give the corresponding acylketene (see scheme 10). In addition to their reactions with nucleophiles, ${ }^{24}$ acylketenes can react as 1,3-oxadienes in inverse demand hetero-Diels-Alder reactions, and this reactivity was exploited in a domino threecomponent synthesis of oxazinones. Thus, we were able to obtain a series of oxazinones $\mathbf{9 6}$ from the microwave irradiation of a 1:1:1 mixture of 2-diazo-1,3-diketone, an aldehyde and a primary amine (Scheme 35). ${ }^{78}$ Under these conditions, the aldehyde and the amine partners react together to give the corresponding imine, while the diazo compound undergoes the Wolff rearrangement to give the corresponding acylketene, which then react with the in situ generated imine. The reaction proceeded well with a variety of aromatic and aliphatic aldehydes, and with alkyl, allyl, propargyl and benzyl amines. With enantiopure primary branched amines a modest chiral induction was observed (e.g. 96d). In the case where both the aldehyde and amine partners are specifically choosen to participate in a subsequent intramolecular Diels-Alder reaction, the pentacyclic oxazinone derivative 96e was obtained allowing the stereocontrolled creation of six chemical bonds and four rings in a single catalyst-free reaction in fair to good yields in regards of the increase of the molecular complexity (Scheme 35). A conceptually related strategy was applied to the synthesis of oxazindiones involving concomitant Wolff and Curtius rearrangments. ${ }^{78}$
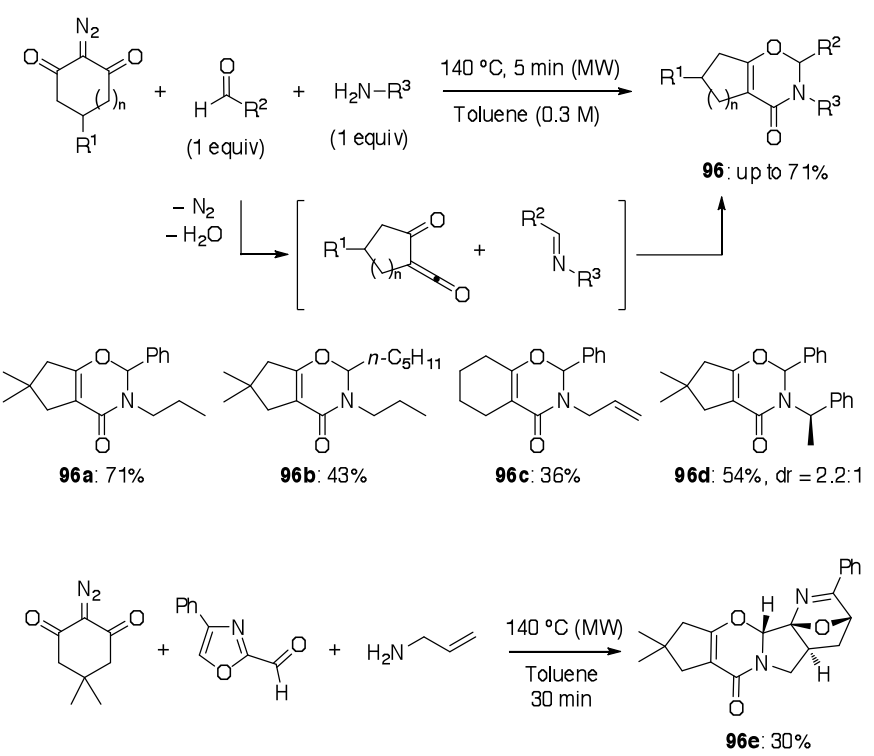

Scheme 35. Microwave-assisted three-component synthesis of oxazinones.

Scheme 34. The MARDi cascade. 


\section{Enantioselective Domino and Multicomponent Reactions}

In the recent years, the growing interest of pharmaceutical and agrochemical companies for the production of enantiopure molecules has led to unprecedented demand for new enantioselective methods. There are many ways to achieve this objective using metal-based catalysts or biocatalysts (enzymes) but these methods, although they may prove useful on a laboratory scale, are limited or even inapplicable to industrial level for various reasons (cost, toxicity, laborious processes, etc.).

On the opposite, organocatalysis, ${ }^{79}$ which has been conceptualized in 2000 by the groups of McMillan ${ }^{80}$ and List ${ }^{81}$ answers perfectly to the principles of "green chemistry" 82 and has already found many applications in synthetic organic chemistry. ${ }^{83}$ One of the first example in enantioselective organocatalysis has been reported independently by two teams (Hajos/Parrish ${ }^{84}$ and Weichert/Sauer/Eder ${ }^{85}$ ) which developed an enantioselective intramolecular aldol condensation catalysed by proline

The purpose of this chapter is to present recent advances in the use of 1,3-dicarbonyl derivatives in domino processes and MCRs involving enantioselective organocatalysis. The reactions will be presented by their type of activation mechanism and the nature of the cascade reaction. ${ }^{86}$

\subsection{Enantioselective Domino Reactions}

Organocatalysis involves several activation modes. ${ }^{83 \mathrm{e}}$ One of the most exploited is probably the enamine-iminium activation which use "proline like" catalysts to form with the substrate (usually an aldehyde or a ketone) an equilibrium between a nucleophilic enamine and an electrophilic iminium that open a wide area of reactivity. This is well understood and has been already well exploited in diverse domino and cascade reactions.

This type of cascade reaction has been discussed previously. Here, the use of an enantiomerically pure organocatalyst allows the control of the chirality in the final product. The discovery of (see introduction), although extraordinary for its time, was not fully exploited until the early 2000s by Barbas, Inspired by the work of Hajos and Parrish, Lerner and List extended this strategy and developed a proline-catalyzed asymmetric Robinson annulation reaction (Scheme 36). ${ }^{81}$ This cascade involves two different processes, namely a Michael addition followed by an aldol condensation.

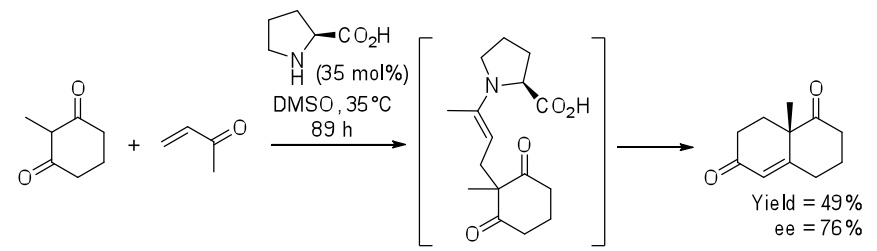

Scheme 36. Enantioselective Robinson annulation.

The cascade Michael-aldol condensation was then developed using $\alpha, \beta$-unsaturated aldehydes and malonate 97 for the synthesis of highly functionalized chiral cyclopentenes 99 using the diphenylprolinol silyl ether $\mathbf{9 8}$ as the organocatalyst (Scheme 37). ${ }^{87}$

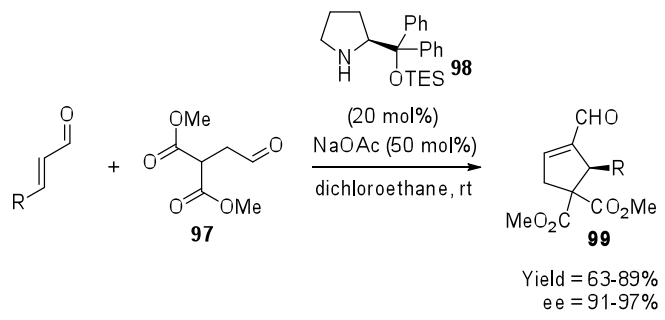

Scheme 37. Enantioselective domino Michael-aldol.

A similar strategy has been employed for the synthesis of cyclohexanones $\mathbf{1 0 1}$ with control of four stereogenic centers using imidazolidine $\mathbf{1 0 0}$ as the organocatalyst (Scheme 38). ${ }^{88}$ The authors suggest that the reaction is initiated by the formation of the Michael adduct with the creation of two stereogenic centers where only one is controlled (the one bearing $\mathrm{Ar}^{1}$ ). Indeed, the carbon atom bearing the ester group racemize quickly under the reaction conditions. Thus, the Michael adduct exists as an equilibrium between syn and anti diastereomers. Fortunately, the second step involving an intramolecular aldol reaction is highly diastereoselective: the cyclization occurs only with the syn Michael adduct. In consequence, only one six-membered ring is formed where the ester group, $\mathrm{Ar}^{1}, \mathrm{Ar}^{2}$ and $\mathrm{R}^{2}$ are in equatorial positions.

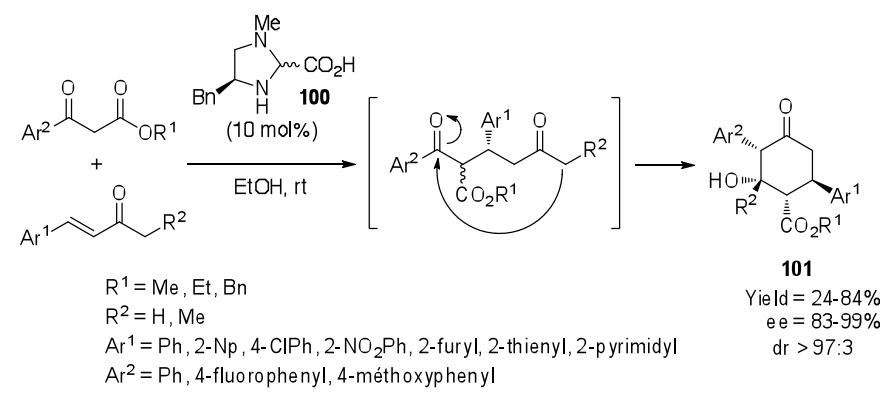

Scheme 38. Enantioselective domino Michael-aldol.

Recently, a new sequence involving iterative Michael additions was reported (Scheme 39). ${ }^{89}$ Again, the iminiumenamine activation is at hand. The advantage of this cascade is the creation and control of three contiguous stereogenic centers; in related Michael-aldol reactions, a single stereogenic center is created, due to the subsequent dehydratation step (see scheme 37). This new methodology is based on highly chemoselective Michael additions and allows easy access to highly functionalized chiral cyclopentanes $\mathbf{1 0 3}$ from $\alpha, \beta$-unsaturated aldehydes and fonctionalized malonates $\mathbf{1 0 2}$.

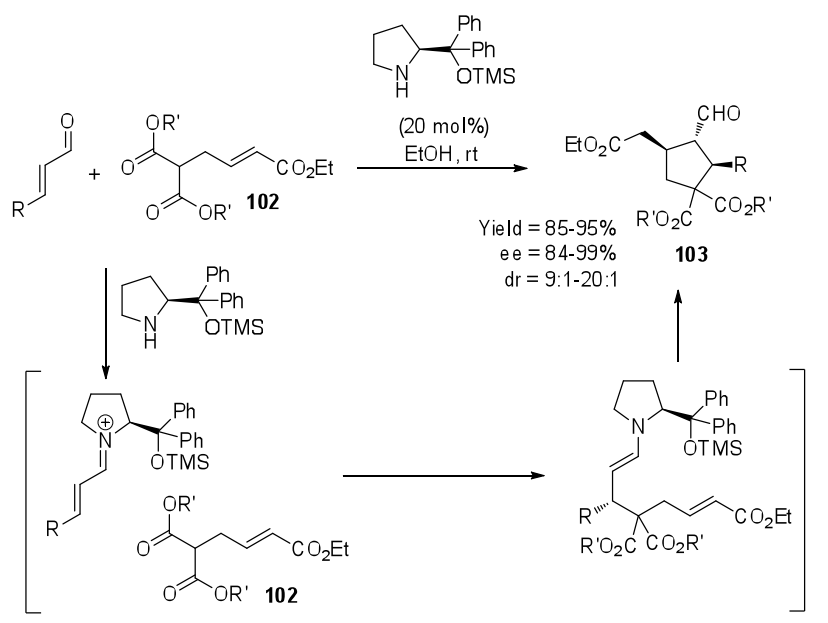


The enantioselective synthesis of epoxycyclohexanones 107 bearing three stereogenic centers has been accomplished by a Michael-Darzens organocatalytic cascade between enal and $\beta$ ketoesters 104 the latter being successively nucleophilic and electrophilic reagent (Scheme 40). ${ }^{90}$ The enantioselective Michael addition is catalyzed by the prolinol derivative and is followed by a Darzens reaction due to the presence in the reaction of a base (sodium acetate) to perform the aldol reaction. In a consecutive step the addition of a stronger base $\left(\mathrm{K}_{2} \mathrm{CO}_{3}\right)$ deprotonates the alcohol $\mathbf{1 0 5}$ and enables the intramolecular $\mathrm{S}_{\mathrm{N}} 2$ reaction to lead to the formation of the epoxide 106. The center alpha to the ketone is partially epimerized which can explain the low diastereoselectivity observed for products $\mathbf{1 0 6}$. However, the saponification of the ester function of $\mathbf{1 0 6}$ followed by decarboxylation gives the diastereomeric pure compounds $\mathbf{1 0 7}$. The good stereoselectivity observed for the other centers was explained by the fact that the aldol reaction is reversible and the irreversible epoxide cyclization is thermodynamically favourable for only one diastereomer of $\mathbf{1 0 5}$ (where both the chlorine and hydroxy groups are in axial position).

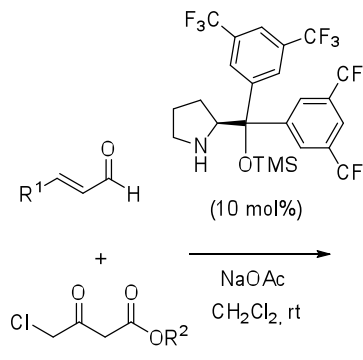

104

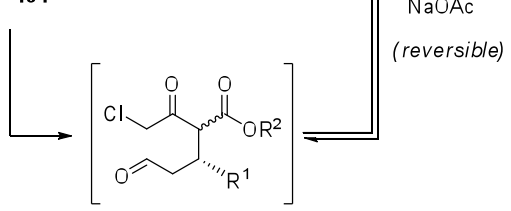

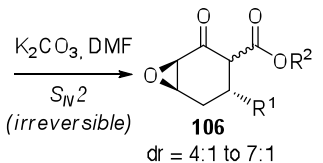

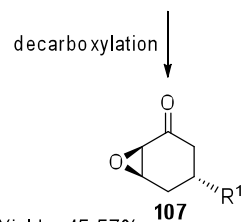

Yield $=45-57 \%$ ee $=84-97 \%$

$\mathrm{dr}>99: 1$
Scheme 40. Organocatalytic enantioselective Michael-Darzens cascade.

Recently, an organocatalytic cascade involving an enantioselective Michael addition, followed by a Knoevenagel condensation between an $\alpha, \beta$-unsaturated aldehyde and dimethyl-3-oxopentadioate (108) was successfully developed (Scheme 41). ${ }^{91}$ This formal [3+3]-carbocycloaddition allows the enantioselective access to cyclohexenone 109. These are not isolated but treated with excess sodium borohydride to give the corresponding saturated cyclohexanol 110 with good yields in two consecutive steps. The authors have shown that the molar ratio of reagents is very important to induce the formation of the product of this cascade. Several substitutions of aromatic or heteroaromatic are possible for the starting aldehyde affording the desired products with excellent enantioselectivities ( $\mathrm{ee}=94$ $99 \%$ ). The use of an additive (benzoic acid) can significantly increase the reaction yield. This work is related to a sequence developed earlier for the enantioselective synthesis of chiral cyclohexenones from tert-butyl 3-oxobutyrate and $\alpha, \beta$ unsaturated aldehydes catalyzed by a diphenylprolinol silyl ether derivative. ${ }^{92}$
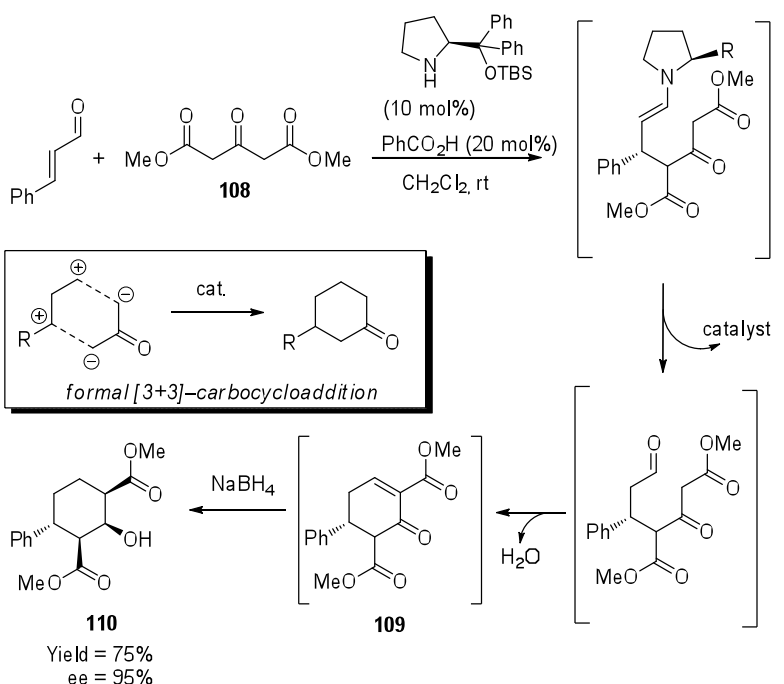

Scheme 41. Organocatalytic enantioselective Michael-Knoevenagel cascade.

Three different groups have developed independently a sequence involving a Michael addition followed by intramolecular alkylation for the synthesis of densely functionalized chiral cyclopropanes 112 (Scheme 42). ${ }^{93,94,95}$ This reaction is rather difficult to realize since the catalyst (a secondary amine) can be easily be poisoned by alkylation of its nitrogen atom by the substrate, hence stopping the reaction. These domino reactions generally use an $\alpha$-halogenated malonate $\mathbf{1 1 1}$ and an $\alpha, \beta$ unsaturated aldehyde to give the corresponding cyclopropanes 112 in very good yields and excellent enantioselectivities. It has been shown that the diastereoselectivity is better when the aldehydes are substituted by an aryl group in the 3 position $(\mathrm{dr}>$ $25: 1)$. In this sequence, it is interesting to note the ambivalent character of the malonic carbon atom which successively plays the role of nucleophile and electrophile.

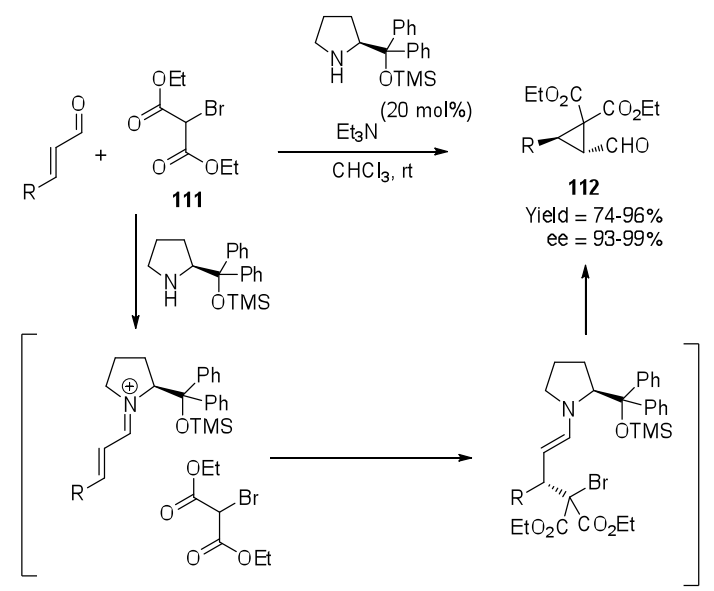

Scheme 42. Organocatalytic enantioselective synthesis of cyclopropanes by a domino Michael-Alkylation reaction.

A similar strategy has been developed for highly enantioselective synthesis of cyclopentanones 114 (Scheme 43). ${ }^{96}$ Nevertheless both the yields and diastereoselectivites are moderate. As before, the 1,3-dicarbonyl derivative $\mathbf{1 1 3}$ is successively nucleophile and electrophile but the reacting centers are different ( $\alpha$ and $\gamma$ ). 


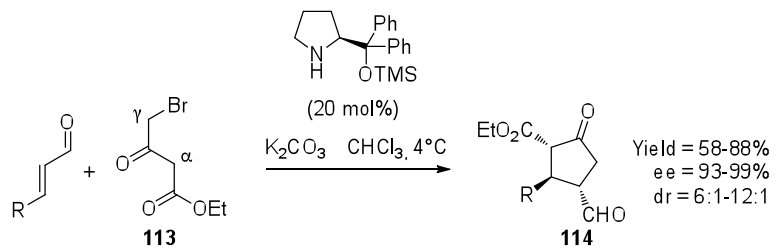

Scheme 43. Access of chiral cyclopentanones using a Michael-alkylation sequence.

The next cascade consists in a Michael addition followed by a Morita-Baylis-Hillman (MBH) reaction. This domino sequence has been serendipitously discovered in an attempt to synthesize the cyclohexanones $\mathbf{1 1 6}$ from an unsaturated aldehyde and the Nazarov reagent 115 by a Michael-Michael cascade reaction (Scheme 44). ${ }^{97}$ Instead of the expected ketone 116, the formation of ketone 117 was observed resulting from a domino reaction involving a Michael addition followed by an intramolecular $\mathrm{MBH}$ reaction.

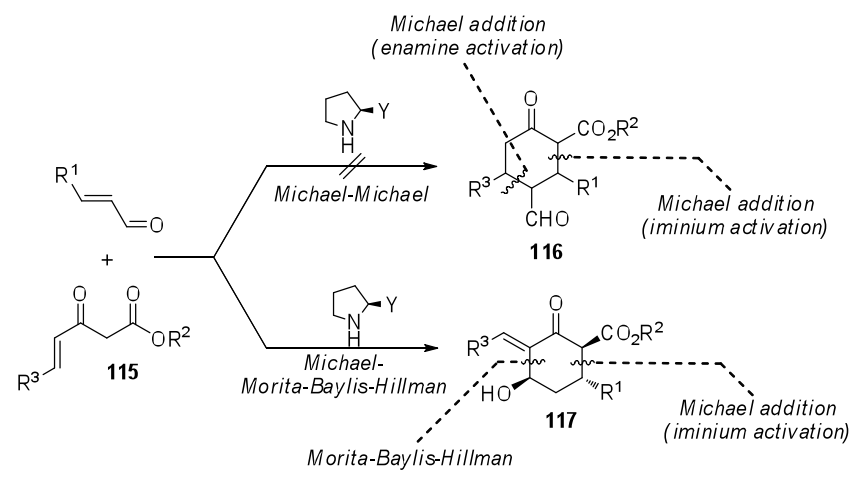

Scheme 44. Organocatalytic enantioselective Michael-MBH cascade.

After optimization of the reaction conditions, the catalyst 118 (10 mol\%) proved to be the best in terms of yield and selectivity combined with benzoic acid $(20 \mathrm{~mol} \%)$ as co-catalyst. This sequence is particularly interesting and extraordinary in a sense that the organocatalyst participates in two distinct catalytic cycles (Scheme 45). In the first cycle, the Michael acceptor is activated as an iminium 119 which reacts with the 1,3-dicarbonyl derivative 116. The aldehyde intermediate $\mathbf{1 2 0}$ is formed and the catalyst is regenerated. Then, it acts as the nucleophile to activate the double bond in the MBH reaction. The authors also showed that the stereoselectivity of the second step is controlled by the center in the $\beta$ position of the aldehyde generated during the Michael addtion.

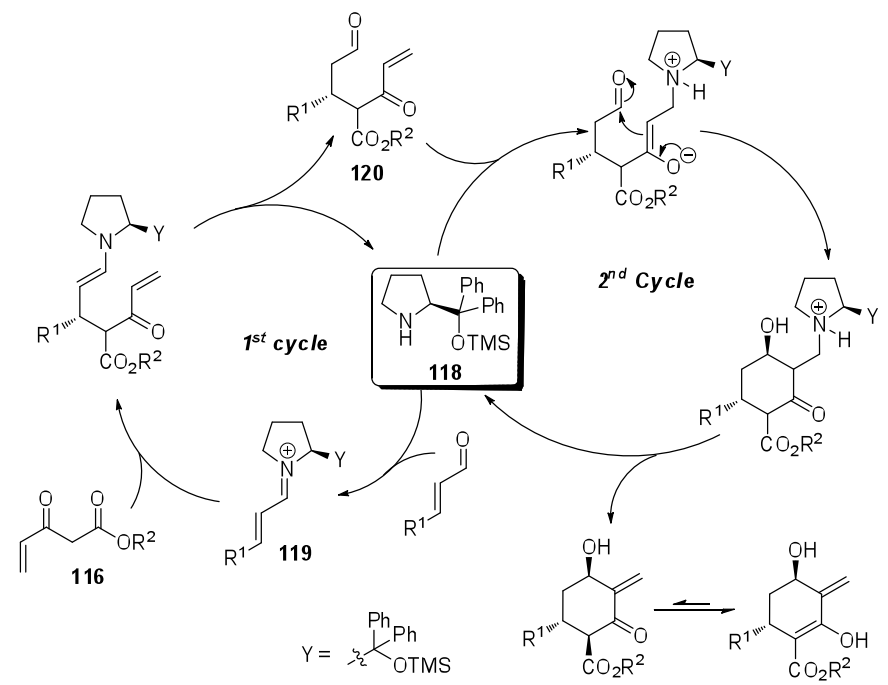

Scheme 45. Mechanism for the Michael-MBH domino reaction.

An enantioselective Michael-acetalization cascade reaction has been realized recently for the synthesis of valuable, biologically active chromenones $\mathbf{1 2 4}$ from cyclic 1,3-diketones 123 and $\alpha, \beta$-unsaturated aldehydes (Scheme 46). ${ }^{98}$ It involves catalytic amounts of diphenylprolinol silyl ether $\mathbf{1 1 8}$ as the catalyst and the desired 2-hydroxychromenones can be isolated in good yields and excellent enantioselectivities.

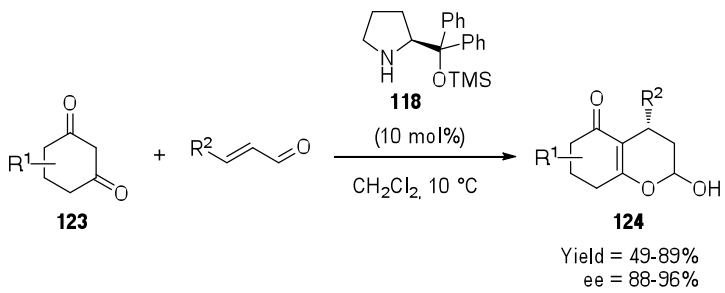

Scheme 46. Enantioselective access to chromenones by a domino Michaelacetalization.

The next cascade reaction is particularly attractive since it allows the fast construction of the quinolizidine skeleton 127 and involves the formation of three new stereocenters with high enantioselectivity and moderate diastereoselectivity (Scheme 47). ${ }^{99}$ The sequence includes an enantioselective Michael addition of the amide $\mathbf{1 2 5}$ on an $\alpha, \beta$-unsaturated aldehyde and an acid catalyzed cyclization of the intermediate acyliminium ion 126.
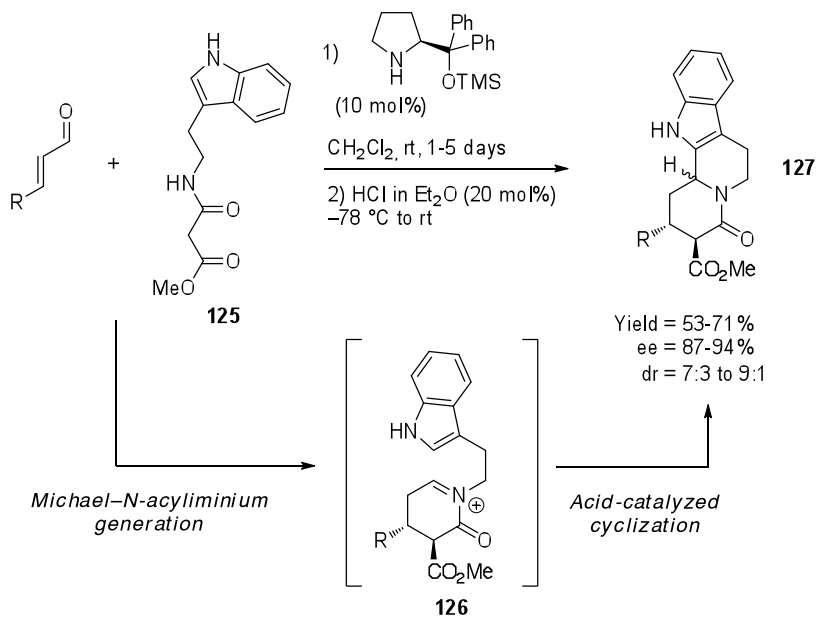

Yield $=53-71 \%$ ee $=87-94 \%$ $d r=7: 3$ to $9: 1$

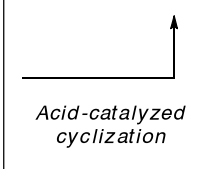

Scheme 47. Enantioselective synthesis of quinalozidines. 
An enantioselective synthesis of $\alpha, \alpha$-disubstituted cyclopentenes was described featuring an N-Heterocyclic Carbene-catalyzed desymmetrization of 1,3-diketones (Scheme 48). ${ }^{100}$ The domino sequence is initiated by the formation of a conjugated Breslowtype intermediate I which undergoes $\beta$-protonation to give enol intermediate II which in turn undergoes an enantioselective aldolization, and the resulting b-lactone undergoes loss of $\mathrm{CO}_{2}$ to afford the chiral cyclopentene $\mathbf{1 2 9}$.

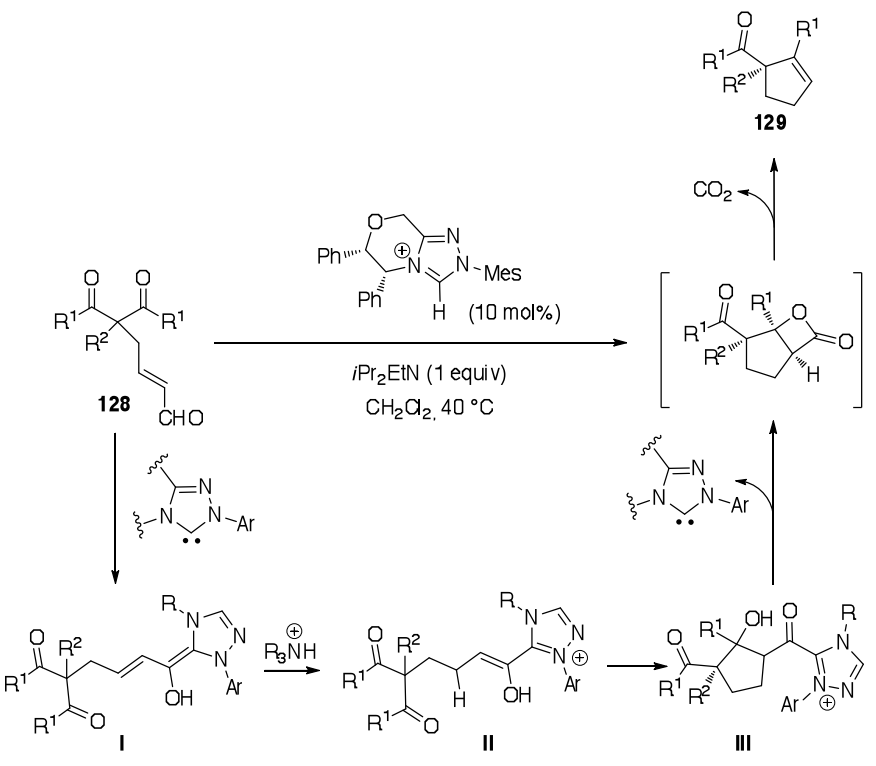

Scheme 48. Enantioselective synthesis of $\alpha, \alpha$-disubstituted cyclopentenes.

In the above examples, the mode of activation of the catalyst involved the reversible formation of a covalent bond between the catalyst and at least one of the substrates. An alternative activation mode, which has its roots back to the eighties, ${ }^{101}$ involves a network of hydrogen bonding interactions. There has been a tremendous number of publication relating the use of this kind of organocatalysts that allow efficient asymmetric transformations. ${ }^{102}$

Inspired by the work of Deslongchamps (see scheme 9), a recent domino reaction involving a double Michael reaction between nitrostyrenes and $\gamma, \delta$-unsaturated $\beta$-ketoesters 130 was reported (Scheme 49). ${ }^{103}$ The thiourea organocatalyst was employed to initiate the first Michael addition. Then, the addition of a stronger base ( $\mathrm{KOH}$ or tetramethylguanidine) is required to achieve cyclization affording the cyclohexanones $\mathbf{1 3 1}$ with the creation and stereocontrol of three contiguous asymmetric carbon atoms. The high stereoselectivity of the second Michael addition can be explained invoking the transition state $\mathbf{A}$ energetically more favorable than the transition state $\mathbf{B}$. This sequence was next employed as a key step in the total synthesis of (-)epibatidine.

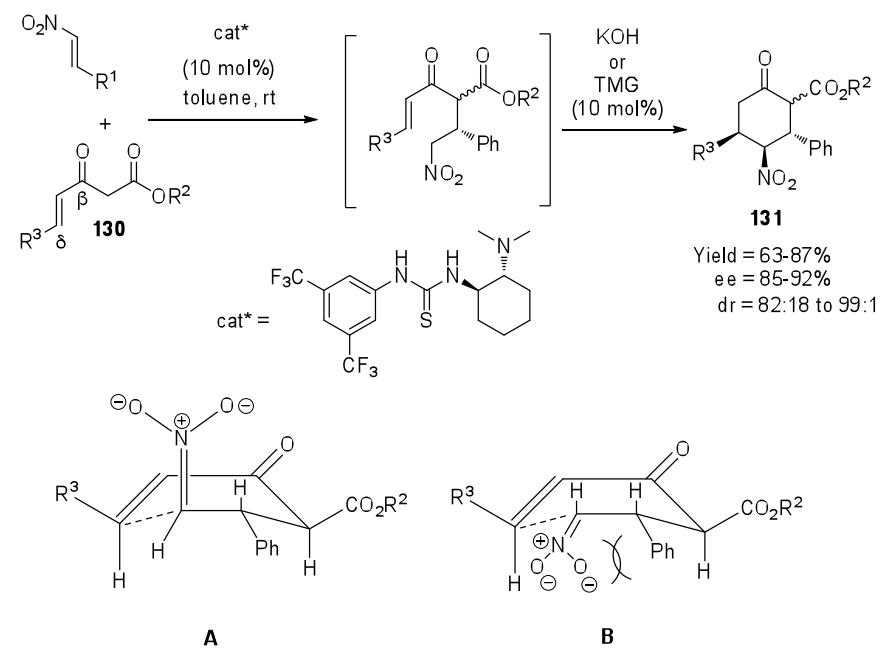

Scheme 49. Enantioselective synthesis of polysubstituted cyclohexanones.

A similar cascade was developed in 2008 for the asymmetric synthesis of polysubstituted cyclopentanes $\mathbf{1 3 3}$ (Scheme 50). ${ }^{104}$ Here also, two Michael acceptors are used in the sequence, the nitroalkene being slightly more reactive than the $\alpha, \beta$-unsaturated ester 132). Thus, the reaction is initiated by the addition of the 1,3-dicarbonyl derivative to the nitroalkene. The nitronate generated in situ then cyclizes following an intramolecular Michael addition to the $\alpha, \beta$-unsaturated ester. The alkaloids derived from cinchona, otherwise used extensively as bifunctional organocatalyst, ${ }^{105}$ activate both the Michael acceptor and donor by hydrogen bonding interactions, which could account for the very good stereoselectivity of this domino reaction.
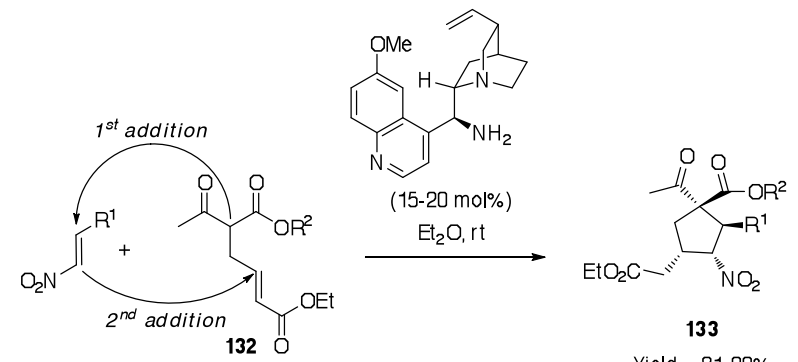

133

$\begin{aligned} \text { Yield } & =81-92 \% \\ \text { ee } & =94-97 \%\end{aligned}$

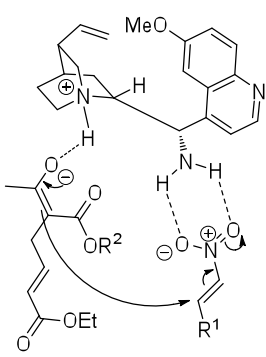

$\mathrm{dr}=95: 5-99: 1$

Scheme 50. Enantioselective Michael-Michael domino reaction.

In parallel to the previous cascade reaction, a Michael-Henry sequence was proposed allowing the access to chiral enantioenriched cyclopentanes from achiral and easily accessible starting materials. ${ }^{106}$ This enantioselective version of an already known transformation, ${ }^{107}$ is very similar to the Michael-Michael sequence described in scheme 50, the only difference being the replacement of the $\alpha, \beta$-unsaturated ester by a ketone moiety. 
A Michael addition-intramolecular alkylation sequence was also used for the enantioselective synthesis of nitrocyclopropanes 136 from methyl 2-bromomalonate (134) and nitroolefins (Scheme 51). ${ }^{108}$ This cascade is related to the one described previously (see scheme 42) but the activation mode is different since in the present case, the organocatalyst $\mathbf{1 3 5}$ activates the substrates through hydrogen bonding interactions.

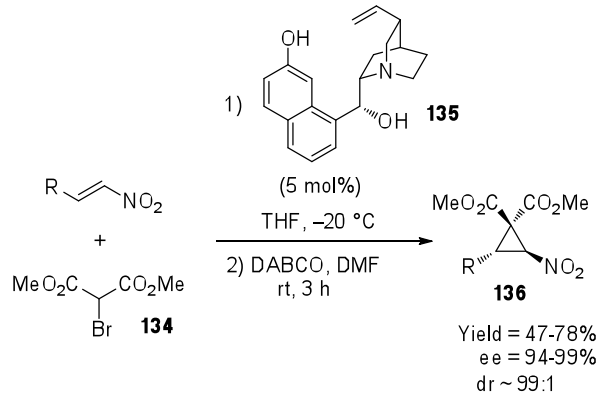

Scheme 51. Highly enantioselective synthesis of nitrocyclopropanes.

Recently, an enantioselective Robinson-type annulation catalyzed by two structurally different chiral phosphoric acids has been described (Scheme 52). ${ }^{109}$ The first acid 139 catalyzed the enantioselective Michael addition of $\beta$-ketoesters 137 to methylvinyl ketone (138) and the second one 140 catalyzed a kinetic resolution in the intramolecular aldol reaction, thereby allowing to reach high enantioselectivities.

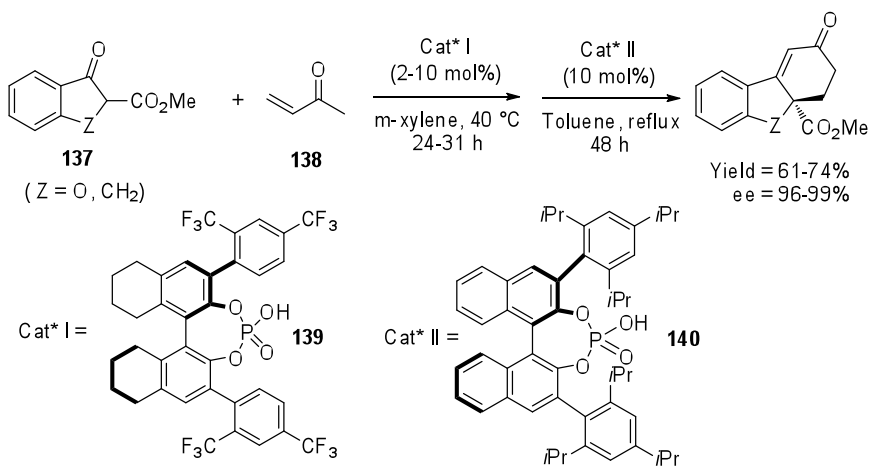

Scheme 52. Enantioselective Robinson annulation reaction catalyzed by chiral phosphoric acids.

\subsection{Enantioselective Multicomponent Reactions}

In this section we will turn our attention to multicomponent enantioselective reactions using 1,3-dicarbonyl derivatives. These are also domino or cascade processes, but they involve at least three substrates with the advantage of having a wider range of variation in the structure of the final product. ${ }^{110}$

The first organocatalytic enantioselective domino multicomponent reaction has been developed in 2001. The Michael acceptor (the arylidene malonate 141) was formed in situ by a Knoevenagel reaction catalyzed by proline between benzaldehyde and diethylmalonate(Scheme 53). ${ }^{111}$ Proline then catalyzed the enantioselective Michael addition of acetone to the akylidene malonate 141. At the time of the development of this reaction, organocatalysis was in its infancy which justify the moderate yield and selectivity observed.
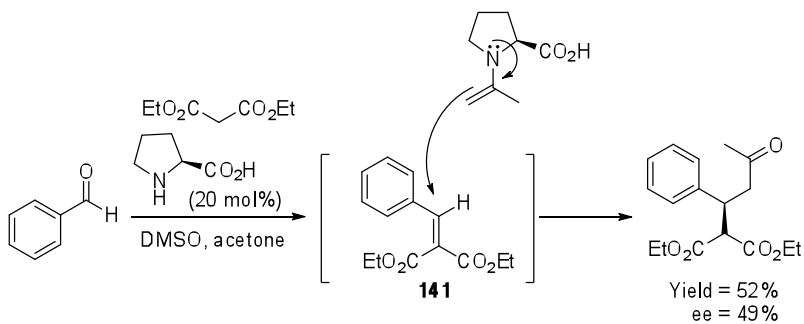

Scheme 53. Enantioselective Knoevenagel-Michael reaction.

An efficient three-component synthesis of functionalized spiro compounds from an enone, an aldehyde and Meldrum's acid involving a Knoevenagel-Diels-Alder domino sequence has been described(Scheme 54). ${ }^{112}$ In this reaction, the prolineanalogue catalyst plays a dual role: it allows the in situ formation of the alkylidene derivative $\mathbf{1 4 2}$ and activates the enone by formation of the enamine 143. Thus, the [4+2]-cycloaddition reaction takes place in a highly diastereo- and enantioselective manner.

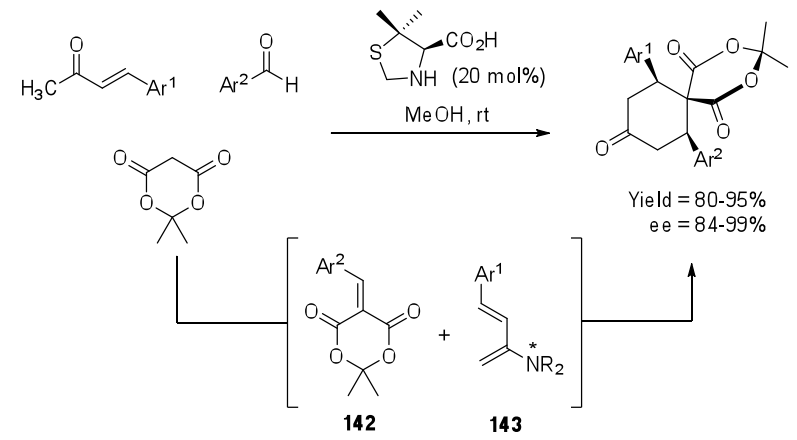

Scheme 54. The Knovenagel-Diels-Alder cascade reaction.

This concept has been extended to a four-component reaction involving a Wittig reaction, a Knoevenagel condensation and a Diels-Alder reaction (Scheme 55). ${ }^{113}$ The difference with the preceding sequence is that the enone is generated in situ by a Wittig reaction between a second equivalent of aldehyde and a phosphorane.

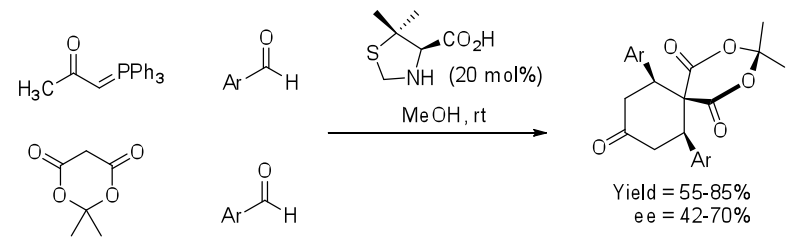

Scheme 55. The four-component Wittig-Knoevenagel-Diels-Alder cascade reaction.

Another very interesting enantioselective multicomponent reaction is the asymmetric [3+2] cycloaddition of aldehydes, diethyl $\alpha$-aminomalonate and nitroalkenes for the synthesis of highly substituted pyrrolidines 145 (Scheme 56). ${ }^{114}$ The reaction involves the in situ formation of azomethine ylides 146, between the aminomalonate 144 and the aldehyde, that reacts with the nitroalkene in a 1,3-dipolar cycloaddition with complete endo selectivity $(>99: 1)$. One limitation is the use of aliphatic aldehydes which do not participate in this reaction. 


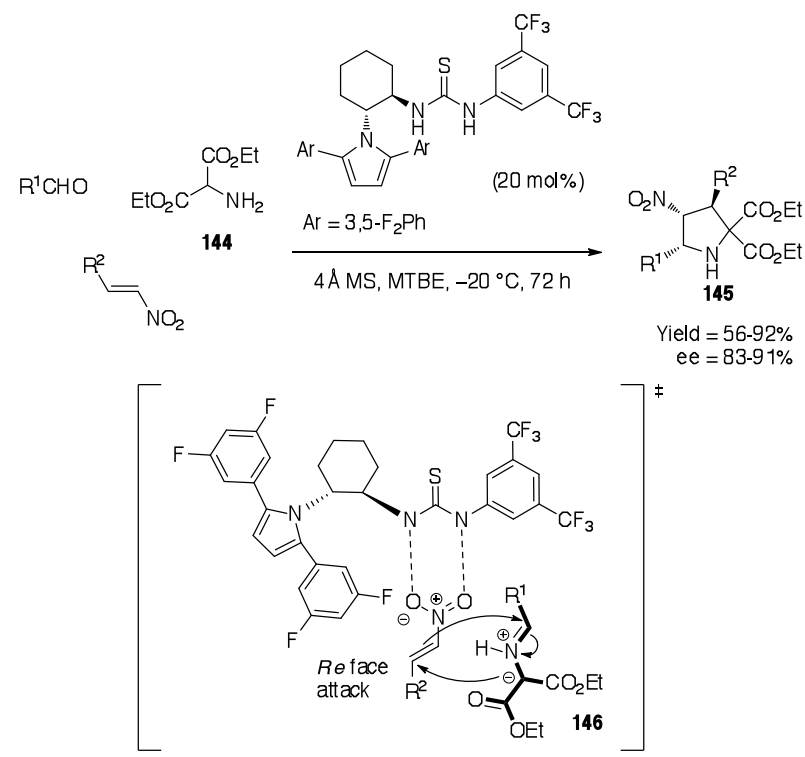

Scheme 56. Enantioselective three-component synthesis of polysubstituted pyrrolidines.

Preliminary results in the catalytic enantioselective Biginelli reaction were reported in 2003, on the use of catalytic amounts of $\mathrm{CeCl}_{3}$ in combination with an amide ligand derived from $(R)-\alpha-$ methylbenzylamine. ${ }^{115}$ Thus, condensation of benzaldehyde with urea and methylacetoacetate in the presence of this catalytic system resulted in the formation of the desired DHPM with $24 \%$ ee. More significantly, in 2005, was reported the first highly enantioselective multicomponent Biginelli reaction using a recyclable ytterbium triflate coordinated with a novel chiral hexadentate ligand 147 bearing tertiary amine, phenol, and pyridine functional groups (Scheme 57). ${ }^{116}$ The desired heterocycles 148 were obtained in high yields with enantiomeric excesses up to $99 \%$.

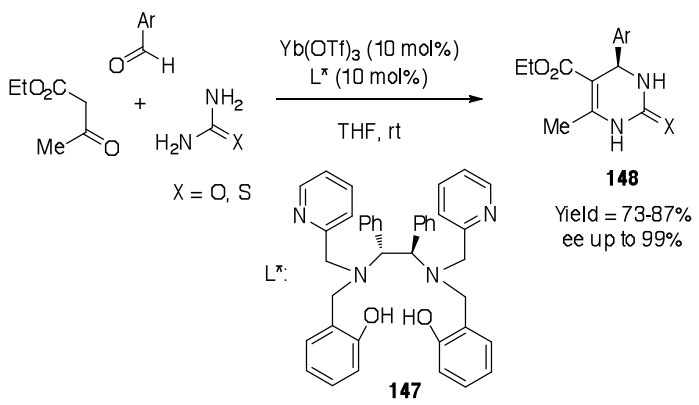

Scheme 57. Ytterbium-catalyzed enantioselective Biginelli reaction.

But the crucial advance was the discovery of the organocatalyzed enantioselective version of the Biginelli reaction in 2006. ${ }^{117,118}$ An enantiomerically pure chiral phosphoric acid 149 was used as a catalyst which allowed access to the 3,4dihydropyrimidin-2-(1H)-ones (DHPM) 150 with very good enantioselectivities (up to $97 \%$ ee, Scheme 58). More recently, the same group has shown that the size of the 3,3'-substituents of the phosphoric acid catalyst has a considerable impact on the control of the stereochemistry, and a fine tuning of these substitutents allowed the synthesis of both enantiomers of the same DHPM. ${ }^{119}$

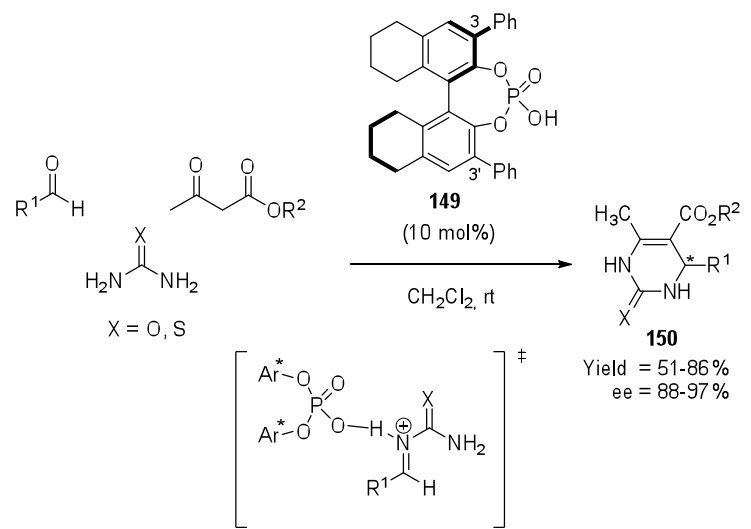

Scheme 58. Organocatalytic enantioselective Biginelli reaction.

This same chiral phosphoric acid organocatalyst 149 was recently employed in the Biginelli reaction as a key step for the enantioselective synthesis of SNAP-7941, a potent melanin concentrating hormone receptor antagonist (Scheme 59). ${ }^{120}$

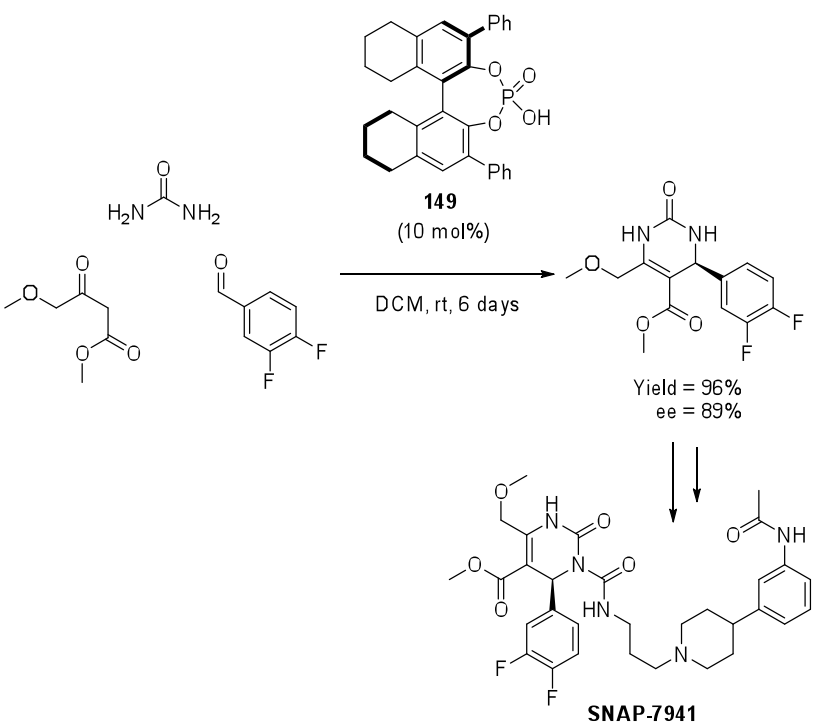

Scheme 59. Enantioselective Biginelli reaction for the synthesis of SNAP7941 .

Organocatalytic enantioselective Biginelli reactions have also been studied using a proline-type organocatalyst in combination with an achiral Brønsted acid co-catalyst. ${ }^{121}$

Alternatively a carbohydrate-based bifunctional primary amine-thiourea catalyst $\mathbf{1 5 1}$ was developed for the enantioselective Biginelli reaction (Scheme 60). ${ }^{122}$ In this case, both the hydrogen-bonding interactions and the enamine activation of the $\beta$-ketoester are invoked to explain the high stereochemical control in the dihydropyrimidine products $\mathbf{1 5 2}$. The use of both a Brønsted acid such as trichlorobenzoic acid (TCBA) and a primary amine salt co-catalysts is required in order to reach high enantioselectivities. 


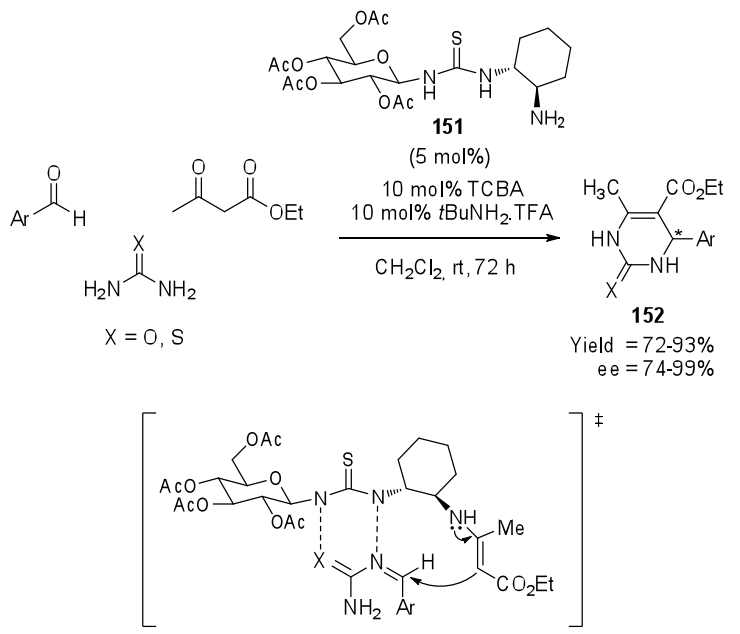

Scheme 60. Enantioselective Biginelli reaction with thiourea-based organocatalyst.

This next example of organocatalyzed multicomponent reaction is an enantioselective version of the modified Hantzsch reaction that we have exposed previously (see section 3.1). Here, the three components, a primary amine, an $\alpha, \beta$-unsaturated aldehyde and an $\alpha, \beta$-ketoester are mixed simultaneously in the presence of an organocatalyst (phosphoric acid 149) for the synthesis of enantiomerically enriched dihydropyridines 153 (ee up to $98 \%$, Scheme 61). ${ }^{123}$ The mechanism involves the formation of an $\alpha, \beta$-unsaturated imine $\mathbf{1 5 4}$ resulting from the condensation between the amine and aldehyde. It is activated through hydrogen bonding interactions with the hydroxyl group of the organocatalyst and undergoes nucleophilic addition of $\beta$ ketoester. Cyclization followed by dehydration allows the formation of the desired DHP $\mathbf{1 5 3}$.

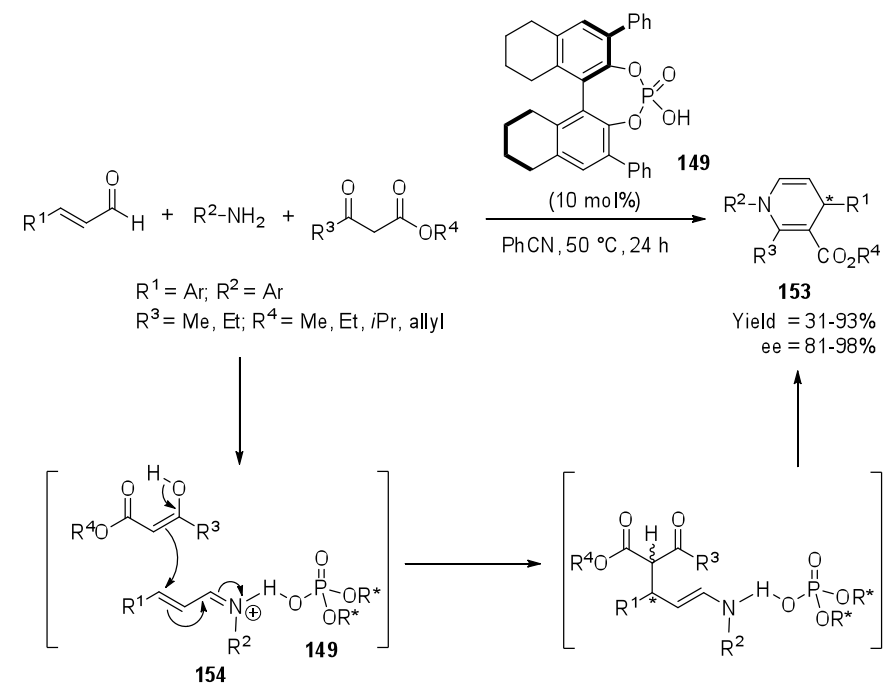

Scheme 61. Enantioselective Hantzsch type reaction.

A similar sequence was developed contemporaneously also for the synthesis of enantioenriched dihydropyridines. ${ }^{124}$ However, this reaction is not considered as a multicomponent reaction since the addition of the third reagent (primary amine) is not simultaneous but takes place after the formation of the Michael adduct (between a $\beta$-ketoester or a $\beta$-diketone and an $\alpha, \beta$-unsaturated aldehyde). Thus, in this specific case, the term of consecutive reaction is more appropriate.
Very recently, an enantioselective four-component reaction has been developed to prepare bicyclic DHPs 156 (Scheme 62). ${ }^{125}$ As before, the use of a chiral phosphoric acid 155 allowed to reach high enantioselectivities.

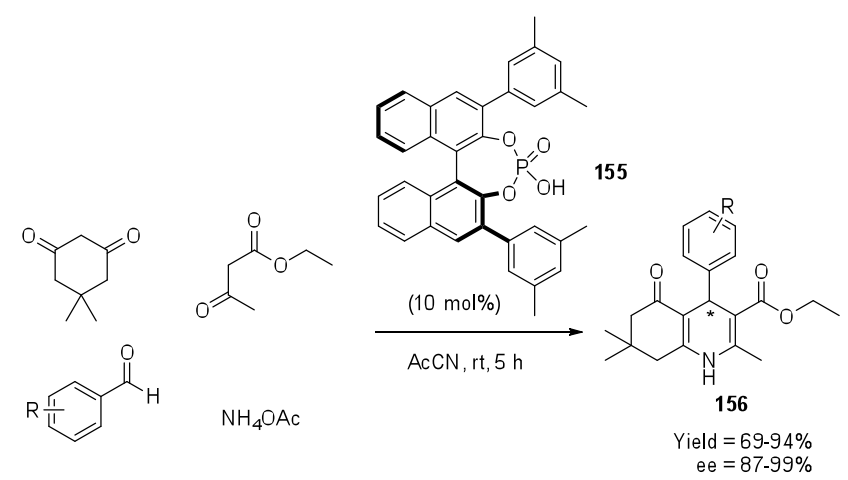

Scheme 62. Access to enantioenriched bicyclic DHPs.

Finally, a promising Michael-Michael-aldol sequence was developed very recently involving two different organocatalysts 98 and 157 with orthogonal activation modes (Scheme 63). ${ }^{126} \mathrm{~A}$ first bifunctional base/Brønsted acid catalysis allowed the enantioselective formation of the Michael adduct 159 and a subsequent iminium catalysis allowed the second Michael addition between iminium 160 and previously formed adduct 159. This organocatalytic enantioselective three-component cascade allowed the synthesis of highly functionalized cyclohexanols $\mathbf{1 5 8}$ in good yields, moderate diastereoselectivities and excellent enantioselectivities.

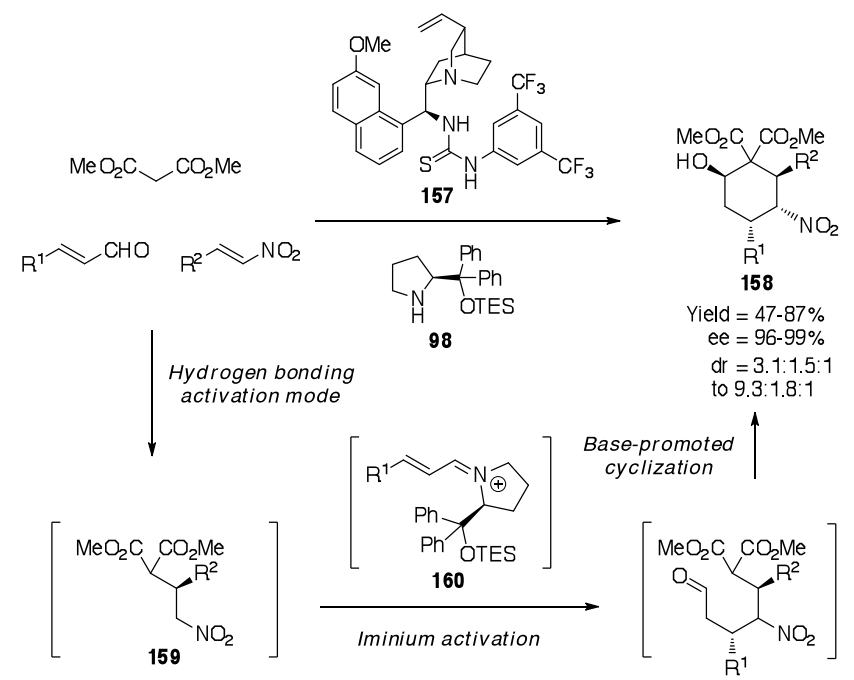

Scheme 63. Dual activation organocatalysis for the enantioselective synthesis of cyclohexanols.

\section{Conclusion}

This compilation of selected examples clearly shows that 1,3dicarbonyl compounds are extremely valuable substrates in domino and/or multicomponent reactions generally involving iterations of simple elemental chemical steps. However, only a perfect mastering of kinetic and thermodynamic parameters can ensure a high control of selectivities.

Of course the use of chiral substrates/auxilaries allows the control of chirality in these reactions, but the most significant contributions are found in enantioselective organocatalysis. These domino and/or multicomponent sequences possess 
considerable assets related to sustainable chemistry. On a practical point of view, the beauty and effectiveness of these cascade reactions are reinforced by the simplicity of the protocols involved in regards of the rapid increase of molecular complexity and functional diversity in the products.

These reactions have already found many applications in the field of combinatorial and medicinal chemistry. The main challenge is now to develop new domino and/or multicomponent reactions allowing straighforward applications in total synthesis. The use of several distinct activation modes in the same sequence is expected to further increase the scope and the eco-compatible character of these new methodologies in organic synthesis.

\section{Acknowledgments}

We thank all the students from our research group who have contributed to the several successful studies reported in this review. Financial support from Centre National de la Recherche Scientifique (CNRS) and the Université Paul Cézanne d'AixMarseille is gratefully acknowledged.

\section{References and notes}

1. Coquerel, Y.; Boddaert, T.; Presset, M.; Mailhol, D.; Rodriguez, $\mathrm{J}$. in Ideas in Chemistry and Molecular Sciences: Advances in Synthetic Chemistry; Chap. 9, pp. 187-202; Pignataro, B., Ed; Wiley-VCH: Weinheim, Germany, 2010 and references therein.

2. Sheldon, R., A.; Arends, I.; Hanefeld, U. Green Chemistry and Catalysis; Wiley-VCH: Weinheim, Germany, 2007 and references therein.

3. Domino reactions in Organic Synthesis; Tietze, L. F.; Bell, H. P.; Brasche, G., Eds.; Wiley-VCH, Weinheim, 2006.

4. Multicomponent Reactions; Zhu, J.; Bienaymé, H., Eds.; Wiley$\mathrm{VCH}$, Weinheim, 2005.

5. (a) Colombo, M.; Peretto, I. Drug Discov. Today 2008, 13, 677684. (b) Hulme, C.; Gore, V. Curr. Med. Chem. 2003, 10, 5180 .

6. (a) Nicolaou, K. C.; Chen, J. S. Chem. Soc. Rev. 2009, 38, 29933009. (b) Touré, B. B.; Hall, D. G. Chem. Rev. 2009, 109, 4439 4486.

7. Simon, C.; Constantieux, T.; Rodriguez, J. Eur. J. Org. Chem. 2004, 4957-4980.

8. For an early review on asymmetric MCRs, see: Ramon, D. J.; Yus, M. Angew. Chem. Int. Ed. 2005, 44, 1602-1634.

9. Danishefsky, S.; Hatch, W. E.; Sax, M.; Abola, E.; Pletcher, J. J. Am. Chem. Soc. 1973, 95, 2410-2411.

10. Filippini, M.-H.; Faure, R.; Rodriguez, J. J. Org. Chem. 1995, 60, 6872-6882.

11. Kozokowski, P. A.; Tückmantel, W. Acc. Chem. Res. 1999, 32, 641-650.

12. Lavoisier-Gallo, T.; Rodriguez, J. J. Org. Chem. 1997, 62, 3787-3788.

13. (a) Baldwin, J. E. J. Chem. Soc., Chem. Commun. 1976, 734 735. (b) Baldwin, J. E.; Kruse, L. I. J. Chem. Soc., Chem. Commun. 1977, 233-234.

14. Ghobsi, A.; Hacini, S.; Wavrin, L.; Gaudel-Siri, A.; Corbères, A.; Nicolas, C.; Bonne, D.; Viala, J.; Rodriguez, J. Eur. J. Org. Chem. 2008, 4446-4453.

15. (a) Lavoisier, T.; Rodriguez. J. Synlett 1996, 339-340. (b) Lavoisier-Gallo, T.; Charonnet, E.; Pons, J.-M.; Rajzman, M.; Faure, R.; Rodriguez. J. Chem. Eur. J. 2001, 7, 1056-1068.

16. Langer, P.; Freiberg, W. Chem. Rev. 2004, 104, 4125-4149.

17. Huckin, S. N.; Weiler, L. J. Am. Chem. Soc. 1974, 96, 1082 1087.

18. Langer, P.; Holtz, E.; Saleh, N. N. R. Chem. Eur. J. 2002, 8, 917-928.

19. Al-Tel, T. H.; Voelter, W. J. Chem. Soc., Chem. Comm. 1995, 239-240.

20. Ahmad, N. M.; Rodeschini, V.; Simpkins, N. S.; Ward, S. E.; Blake, A. J. J. Org. Chem. 2007, 72, 4803-4815.

21. Kashihara, H.; Shinoki, H.; Suemune, H.; Sakai, K. Chem. Pharm. Bull. 1986, 34, 4527-4532.
22. Zhang, H.; Reddy, M. S.; Phoenix, S.; Deslongchamps, P. Angew. Chem. Int. Ed. 2008, 47, 1272-1275.

23. (a) Kirmse, W. Eur. J. Org. Chem. 2002, 2193-2256. (b) Wentrup, C.; Heilmayer, W.; Kollenz, G. Synthesis 1994, 12191248.

24. Presset, M.; Coquerel, Y.; Rodriguez, J. J. Org. Chem. 2009, 74, 415-418.

25. Hantzsch, A. Justus Liebigs Ann. Chem. 1882, 215, 1-82.

26. Cotterill, I. C.; I, Usyatinsky, A. Y.; Arnold, J. M.; Clark, D. S.; Dordick, J. S.; Michels, P. C.; Khmelnitsky, Y. L. Tetrahedron Letters 1998, 39, 1117-1120.

27. Rose, U.; Draeger, M. J. Med. Chem. 1992, 35, 2238-2243.

28. Moseley, J. D. Tetrahedron Lett. 2005, 46, 3179-3181.

29. (a) Dondoni, A.; Massi, A. Acc. Chem. Res. 2006, 39, 451-463. (b) Dondoni, A.; Massi, A.; Aldhoun, M. J. Org. Chem. 2007, 72, 7677-7687.

30. Ducatti, D. R. B.; Massi, A.; Noseda, M. D.; Duarte, M. E. R.; Dondoni, A. Org. Biomol. Chem. 2009, 7, 1980-1986.

31. Chebanov, V. A.; Saraev, V. E.; Desenko, S. M.; Chermenko, V. N.; Knyazeva, I. V.; Groth, U.; Glasnov, T. N.; Kappe, C. O. J. Org. Chem. 2008, 73, 5110-5118.

32. Shaabani, A.; Rahmati, A.; Rezayan, A. H.; Darvishi, M.; Badri, Z.; Sarvari, A. QSAR Comb. Sci. 2007, 26, 973-979.

33. Biginelli, P . Gazz. Chim. Ital. 1893, 23, 360-413.

34. (a) Kappe, C. O. Eur. J. Med. Chem. 2000, 35, 1043-1052. (b) Kappe, C. O. QSAR Comb. Sci. 2003, 22, 630-645.

35. (a) Atwal, K. S.; Swanson, B. N.; Unger, S. E.; Floyd, D. M.; Moreland, S.; Hedberg, A.; O'Reilly, B. C. J. Med. Chem. 1991, 34, 806-811. (b) Maliga, Z.; Kapoor, T. M.; Mitchison, T. J. Chem. Biol. 2002, 9, 989-996. (c) Debonis, S.; Simorre, J. P.; Crevel, I.; Lebeau, L.; Skoufias, D. A.; Blangy, A.; Ebel, C.; Gans, P.; Cross ; R.; Hackney, D. D.; Wade, R. H.; Kozielski, F. Biochemistry 2003, 42, 338-349.

36. Gong, L.-Z.; Chen, X.-H.; Xu, X.-Y. Chem. Eur. J. 2007, 13, 8920-8926.

37. Atwal, K. S.; Rovnyak, G. C.; Kimball, S. D.; Floyd, D. M.; Moreland, S.; Swanson, B. N.; Gougoutas, J. Z.; Smillie, K. M.; Malley, M. F. J. Med. Chem. 1990, 33, 2629-2635.

38. Dondoni, A.; Massi, A.; Sabbatini, S. Tetrahedron Lett. 2002, 43, 5913-5916.

39. (a) Schnell, B.; Krenn, W.; Faber, K.; Kappe, C. O. J. Chem. Soc., Perkin Trans. 1 2000, 4382-4389. (b) Schnell, B.; Strauss, U. T.; Verdino, P.; Faber, K.; Kappe, C. O. Tetrahedron: Asymmetry 2000, 11, 1449-1453.

40. Sidler, D. R.; Barta, N.; Li, W.; Hu, E.; Matty, L.; Ikemoto, N.; Campbell, J. S.; Chartrain, M.; Gbewonyo, K.; Boyd, R.; Corley, E. G.; Ball, R. G.; Larsen, R. D.; Reider, P. J. Can. J. Chem. 2002, 80, 646-652.

41. Dondoni, A.; Massi, A.; Sabbatini, S.; Bertolasi, V. J. Org. Chem. 2002, 67, 6979-6994.

42. Kappe, C. O.; Uray, G.; Roschger, P.; Lindner, W.; Kratky, C.; Keller, W. Tetrahedron 1992, 48, 5473-5480.

43. Mukhopadhyay, M.; Bhatia, B.; Iqbal, J. Tetrahedron Lett. 1997, 38, 1083-1086.

44. Barluenga, J.; Viado, A. L.; Aguilar, E.; Fustero, S. J. Org. Chem. 1993, 58, 5972-5975.

45. Rao, I. N.; Prabhakaran, E. N.; Das, S. K.; Iqbal, J. J. Org. Chem. 2003, 68, 4079-4082.

46. (a) Pandey, G.; Singh, R. P.; Garg, A.; Singh, V. K. Tetrahedron Lett. 2005, 46, 2137-2140. (b) Bhat, R. P.; Raje, V. P.; Alexander, V. M.; Patil, S. B.; Samant, S. D. Tetrahedron Lett. 2005, 46, 4801-4803. (c) Das, B.; Reddy, K. R.; Ramu, R.; Thirupathi, P.; Ravikanth, B. Synlett, 2006, 1756-1758. (d) Khan, A. T.; Choudhury, L. H.; Parvin, T.; Ali, M. A. Tetrahedron Lett. 2006, 47, 8137-8141. (e) Khan, A. T.; Parvin, T.; Choudhury, L. H. Tetrahedron 2007, 63, 5593-5601. (f) Ghosh, R.; Maiti, S.; Ghosh, S.; Mukherjee, A. K. Synthesis 2007, 190-196. (g) Mirjafary, Z.; Saeidian, H.; Sadeghi, A.; Moghaddam, F. M. Catal. Commun. 2008, 9, 299-306. (h) Das, B.; Srilatha, M.; Veeranjaneyulu, B.; Rao, B. R. Synthesis, 2010, 803-806.

47. Shinu, V. S.; Sheeja, B.; Purushothaman, E.; Bahulayan, D. Tetrahedron Lett. 2009, 50, 4838-4843.

48. Mao, H.; Wan, J.; Pan, Y. Tetrahedron 2009, 65, 1026-1032.

49. Fujioka, H.; Murai, K.; Kubo, O.; Ohba, Y.; Kita, Y. Org. Lett. 2007, 9, 1687-1690.

50. Sotoca, E.; Allais, C.; Constantieux, T.; Rodriguez, J. Org. Biomol. Chem. 2009, 7, 1911-1920. 
51. Sotoca, E.; Constantieux, T.; Rodriguez, J. Synlett 2008, 13131316.

52. Murai, K.; Nakatani, R.; Kita, Y.; Fujioka, H. Tetrahedron 2008, 64, 11034-11040.

53. List, B. Angew. Chem. Int. Ed. 2010, 49, 1730-1734.

54. (a) Tietze, L. F.; Beifuss, U. Angew. Chem. Int. Ed. 1993, 32, 131-163. (b) Tietze, L. F. Chem. Rev. 1996, 96, 115-136. (c) Tietze, L. F.; Modi, A. Med. Res. Rev. 2000, 20, 304-322.

55. Tietze, L. F.; Rackelmann, N.; Müller, I. Chem. Eur. J. 2004, 10, 2722-2731.

56. Jiménez-Alonso, S.; Estévez-Braun, A.; Ravelo, Á. G.; Zárate, R.; López, M. Tetrahedron 2007, 63, 3066-3074.

57. Radi, M.; Bernardo, V.; Bechi, B.; Castagnolo, D.; Pagano, M.; Botta, M. Tetrahedron Lett. 2009, 50, 6572-6575.

58. Boisbrun, M.; Kovács-Kulyassa, Á.; Jeannin, L.; Sapi, J.; Toupet, L.; Laronze, J.-Y. Tetrahedron Lett. 2000, 41, 97719775.

59. Dardennes, E.; Kovács-Kulyassa, Á.; Renzetti, A.; Sapi, J.; Laronze, J.-Y. Tetrahedron Lett. 2003, 44, 221-223.

60. Dardennes, E.; Kovács-Kulyassa, Á.; Boisbrun, M.; Petermann, C.; Laronze, J.-Y.; Sapi, J. Tetrahedron : Asymmetry 2005, 16, 1329-1339.

61. (a) Vasuki, G.; Kumaravel, K. Tetrahedron Lett. 2008, 49, 5636-5638. (b) Nagarajan, A. S.; Reddy, B. S. R. Synlett 2009, 2002-2004.

62. Li, M.; Yang, W.-L.; Wen, L.-R.; Li, F.-Q. Eur. J. Org. Chem. 2008, 2751-2758.

63. Cui, H.-F.; Dong, K.-Y.; Zhang, G.-W.; Wang, L.; Ma, J.A Chem. Commun. 2007, 2284-2286.

64. Tokoroyama, T. Eur. J. Org. Chem. 2010, DOI: 10.1002/ ejoc.200901130.

65. Liéby-Muller, F.; Simon, C.; Constantieux, T.; Rodriguez, J. QSAR Comb. Sci 2006, 25, 432-438.

66. Sanchez Duque, M.; Allais, C.; Isambert, N.; Constantieux, T.; Rodriguez, J. Topics in Heterocyclic Chemistry, R. Orru Ed., Springer-Verlag (Berlin), 2010, in press (DOI $10.1007 / 7081201026$

67. Shibuya, M.; Jaisli, F.; Eschenmoser, A. Angew. Chem. Int. Ed. Engl. 1979, 18, 636-637.

68. Simon, C.; Peyronel, J.-F.; Rodriguez, J. Org. Lett. 2001, 3, 2145-2148.

69. Noël, R.; Fargeau-Bellassoued, M.-C.; Vanucci-Bacqué, C.; Lhommet, G. Synthesis 2008, 1948-1954.

70. Liéby-Muller, F.; Constantieux, T.; Rodriguez, J. Synlett 2007, $1323-1325$.

71. Simon, C.; Liéby-Muller, F.; Peyronel, J.-F.; Constantieux, T.; Rodriguez, J. Synlett 2003, 2301-2304.

72. Sridharan, V.; Menéndez, J. C. Org. Lett. 2008, 10, 4303-4306.

73. Liéby-Muller, F.; Constantieux, T.; Rodriguez, J. J. Am. Chem. Soc. 2005, 127, 17176-17177.

74. Coquerel, Y.; Filippini, M.-H.; Bensa, D.; Rodriguez, J. Chem. Eur. J. 2008, 14, 3078-3092.

75. Coquerel, Y.; Bensa, D.; Moret, V.; Rodriguez, J. Synlett, 2006, 2751-2754.

76. Coquerel, Y.; Bensa, D.; Doutheau, A.; Rodriguez, J. Org. Lett. 2006, 8, 4819-4822.

77. Reboul, I.; Boddaert, T.; Coquerel, Y.; Rodriguez, J. Eur. J. Org. Chem. 2008, 5379-5382.

78. Presset, M.; Coquerel, Y.; Rodriguez, J. Org. Lett. 2009, 11, 5706-5709.

79. The first example of organocatalysis is in fact the Knovenagel condensation between benzaldehyde, ethyl-3-oxobutanoate catalyzed by piperdine; Knoevenagel, E. Chem. Ber. 1896, 29, $172-174$.

80. Ahrendt, K. A.; Borths, C. J.; MacMillan, D. W. C. J. Am. Chem. Soc. 2000, 122, 4243-4244.

81. List, B.; Lerner, R. A.; Barbas III, C. F. J. Am. Chem. Soc. 2000, 122, 2395-2396.

82. For a recent special issue on green chemistry see: Chem. Rev. 2007, 107, 2167-2820.

83. For recent reviews on organocatalysis, see: (a) Bertelsen, S.; Jørgensen, K. A. Chem. Soc. Rev. 2009, 38, 2178-2189. (b) Dondoni, A.; Massi, A. Angew. Chem. Int. Ed. 2008, 47, 46384660. (c) Barbas III, C. F. Angew. Chem. Int. Ed. 2008, 47, 4247. (d) Melchiorre, P.; Marigo, M.; Carlone, A.; Bartoli, G. Angew. Chem. Int. Ed. 2008, 47, 6138-6171. (e) MacMillan, D. W. C. Nature 2008, 455, 304-308. (f) Chem. Rev. 2007, 107(12), Special issue on asymmetric organocatalysis. (g)
Enantioselective Organocatalysis; Dalko, P. I., Ed.; WileyVCH, Weinheim, 2007. (h) Asymmetric Organocatalysis: From Biomimetic Concepts to Applications in Asymmetric Synthesis; Berkessel, A.; Groger, H.; MacMillan, D. W. C., Eds.; WileyVCH, Weinheim, 2005.

84. Hajos, Z. G.; Parrish, D. R. German Patent DE 2102623, 1971. (b) Hajos, Z. G.; Parrish, D. R. J. Org. Chem. 1974, 39, 16151621 .

85. Eder, U.; Sauer, G. R.; Wiechert, R. German Patent DE 2104757, 1971.

86. For a review on organocatalytic cascades, see: Yu, X.; Wang, W. Org. Biomol. Chem., 2008, 6, 2037-2046.

87. Wang, J.; Li, H.; Xie, H.; Zu, L.; Shen, X.; Wang, W. Angew. Chem. Int. Ed. 2007, 46, 9050-9053.

88. Halland, N.; Aburel, P. S.; Jørgensen, K. A. Angew. Chem. Int. Ed. 2004, 43, 1272-1277.

89. Zu, L.; Li, H.; Xie, H.; Wang, J.; Jiang, W.; Tang, Y.; Wang, W. Angew. Chem. Int. Ed. 2007, 46, 3732-3734.

90. Marigo, M.; Bertelsen, B.; Landa, A.; Jørgensen, K. A. J. Am. Chem. Soc. 2006, 128, 5475-5479.

91. Hayashi, T.; Toyoshima, M.; Gotoh, H.; Ishikawa, H. Org. Lett. 2009, 11, 45-48.

92. Carlone, A.; Marigo, M.; North, C.; Landa, A.; Jørgensen, K. A. Chem. Comm. 2006, 4928-4930.

93. Xie, H.; Zu, L.; Li, H.; Wang, J.; Wang, W. J. Am. Chem. Soc. 2007, 129, 10886-10894.

94. Rios, R.; Sunden, H.; Vesely, J.; Zhao, G.-L. Dziedzic, P.; Cordova, A. Adv. Synth. Catal. 2007, 349, 1028-1032.

95. Hansen, H. M.; Longbottom, D. A.; Ley, S. V. Chem. Commun. 2006, 4838-4840.

96. Rios, R.; Vesely, J.; Sunden, H.; Ibrahem, I.; Zhao, G.-L.; Cordova, A. Tetrahedron Lett. 2007, 48, 5835-5839.

97. Cabrera, S.; Aleman, J.; Bolze, P.; Bertelsen, S.; Jørgensen, K. A. Angew. Chem. Int. Ed. 2008, 47, 121-125.

98. Rueping, M.; Sugiono, E.; Merino, E. Chem. Eur. J. 2008, 14, 6329-6332.

99. (a) Zhang, W.; Franzén, J. Adv. Synth. Catal. 2010, 352, 499518. (b) Franzén, J.; Fisher, A. Angew. Chem. Int. Ed. 2009, 48, $787-791$.

100. Wadamoto, M.; Phillips, E. M.; Reynolds, T. E.; Scheidt, K. A. J. Am. Chem. Soc. 2007, 129, 10098-10099.

101. (a) Hiemstra, H.; Wynberg, H. J. Am. Chem. Soc. 1981, 103, 417-430. (b) Oku, J. I.; Inoue, S. J. Chem. Soc., Chem. Comm. 1981, 229-230. (c) Dolling, U. H.; Davis, P.; Grabowski, E. J. J. J. Am. Chem. Soc. 1984, 106, 446-447.

102. For a review on hydrogen bond catalysis, see: Doyle, A. G.; Jacobsen, E. N. Chem. Rev. 2007, 107, 5713-5743.

103. Hoashi, Y.; Yabuta, T.; Yuan, P.; Miyabe, H.; Takemoto, Y. Tetrahedron 2006, 62, 365-374.

104. Tan, B.; Shi, Z.; Chua, P. J.; Zhong, G. Org. Lett. 2008, 10, 3425-3428.

105. (a) Marcelli, T.; van Maarseveen, J. H.; Hiemstra, H. Angew. Chem. Int. Ed. 2006, 45, 7496-7504. (b) Cinchona Alkaloids in Synthesis and Catalysis; Song, C. E., Ed.; Wiley-VCH, Weinheim, 2009.

106. Tan, B.; Chua, P. J.; Zeng, X.; Lu, M.; Zhong, G. Org. Lett. 2008, 10, 3489-3492.

107. Seebach, D.; Ehrig, V. Angew. Chem. Int. Ed. 1974, 13, 400401.

108. Xuan, Y.-n.; Nie, S.-z.; Dong, L.-t.; Zhang, J.-m.; Yan, M. Org. Lett. 2009, 11, 1583-1586.

109. Akiyama, T.; Katoh, T.; Mori, K. Angew. Chem. Int. Ed. 2009, 48, 4226-4228.

110. (a) Ramón, D. J.; Yus, M. Angew. Chem. Int. Ed. 2005, 44, 1602-1634. (b) Guillena, G.; Ramón, D. J.; Yus, M. Tetrahedron: Asymmetry 2007, 18, 693-700.

111. Betancort, J. M.; Sakthivel, K.; Thayumanavan, R.; Barbas III, C. F. Tetrahedron Lett. 2001, 42, 4441-4444.

112. Ramachary, D. B.; Chowdari, N. S.; Barbas III, C. F. Angew. Chem. Int. Ed. 2003, 42, 4233-4237.

113. Ramachary, D. B.; Barbas III, C. F. Chem. Eur. J. 2004, 10, 5323-5331.

114. Liu, Y.-K.; Liu, H.; Du, W.; Yue, L.; Chen, Y.-C. Chem. Eur. J. 2008, 14, 9873-9877.

115. Muñoz-Muñiz, O.; Juaristi, E. Arkivoc 2003, xi, 16-26.

116. Huang, Y. J.; Yang, F. Y.; Zhu, C. J. J. Am. Chem. Soc. 2005, 127, 16386-16387. 
117. Chen, X.-H.; Xu, X.-Y.; Liu, H.; Cun, L.-F.; Gong, L.-Z. J. Am. Chem. Soc. 2006, 128, 14802-14803.

118. For a review, see: Gong, L.-Z.; Chen, X. H.; Xu X.-Y. Chem. Eur. J. 2007, 13, 8920-8926.

119. Li, N.; Chen, X.-H.; Song, J.; Luo, S.-W.; Fan, W.; Gong, L.-Z. J. Am. Chem. Soc. 2009, 131, 15301-15310.

120. Goss, J. M.; Schaus, S. E. J. Org. Chem. 2008, 73, 7651-7656.

121. Xin, J.; Chang, L.; Hou, Z.; Shang, D.; Liu, X.; Feng, X. Chem. Eur. J. 2008, 14, 3177-3181.

122. Wang, Y.; Yang, H.; Yu, J.; Miao, Z.; Chen, R. Adv. Synth Catal. 2009, 351, 3057-3062.

123. Jiang, J.; Yu, J.; Sun, X.-X.; Rao, Q.-Q.; GONG, L.-Z. Angew. Chem. Int. Ed. 2008, 47, 2458-2462.

124. Franke, P. T.; Johansen, R. L.; Bertelsen, S.; Jørgensen, K. A. Chem. Asian J. 2008, 3, 216-224.

125. Evans, C. G.; Gestwicki, J. E. Org. Lett. 2009, 11, 2957-2959.

126. Wang, Y.; Han, R.-G.; Zhao, Y.-L.; Yang, S.; Xu, P.-F.; Dixon, D. J. Angew. Chem. Int. Ed. 2009, 48, 9834-9838. 